\title{
A Presynaptic Function of Shank Protein in Drosophila
}

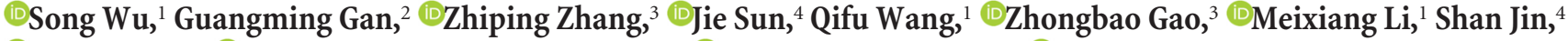 \\ - Juan Huang, ${ }^{5}$ - Ulrich Thomas, ${ }^{6}$ Yong-hui Jiang, ${ }^{7}{ }^{\circ}$ Yan Li, ${ }^{3}$ Rui Tian, ${ }^{1}$ and ${ }^{-Y}$ Yong Q. Zhang ${ }^{1}$ \\ ${ }^{1}$ Key Laboratory for Molecular and Developmental Biology, Institute of Genetics and Developmental Biology, University of Chinese Academy of Sciences, \\ Beijing 100101, China, ${ }^{2}$ Medical School, Southeast University, Nanjing 210009, China, ${ }^{3}$ Key Laboratory of Brain and Cognitive Sciences, Institute of \\ Biophysics, Chinese Academy of Sciences, Beijing 100101, China, ${ }^{4}$ College of Life Science, Hubei University, Wuhan, Hubei 430062, China, ${ }^{5}$ School of Basic \\ Medical Sciences, Nanjing Medical University, Nanjing 210029, China, ${ }^{6}$ Leibniz Institute for Neurobiology, Magdeburg 39118, Germany, and 7Departments \\ of Pediatrics and Neurobiology, Duke University School of Medicine, Durham, North Carolina 27710
}

Human genetic studies support that loss-of-function mutations in the SH3 domain and ankyrin repeat containing family proteins (SHANK1-3), the large synaptic scaffolding proteins enriched at the postsynaptic density of excitatory synapses, are causative for autism spectrum disorder and other neuropsychiatric disorders in humans. To better understand the in vivo functions of Shank and facilitate dissection of neuropathology associated with SHANK mutations in human, we generated multiple mutations in the Shank gene, the only member of the SHANK family in Drosophila melanogaster. Both male and female Shank null mutants were fully viable and fertile with no apparent morphological or developmental defects. Expression analysis revealed apparent enrichment of Shank in the neuropils of the CNS. Specifically, Shank coexpressed with another PSD scaffold protein, Homer, in the calyx of mushroom bodies in the brain. Consistent with high expression in mushroom body calyces, Shank mutants show an abnormal calyx structure and reduced olfactory acuity. These morphological and functional phenotypes were fully rescued by pan-neuronal reexpression of Shank, and only partially rescued by presynaptic but no rescue by postsynaptic reexpression of Shank. Our findings thus establish a previously unappreciated presynaptic function of Shank.

Key words: autism; mushroom body calyx; PSD; Shank; synaptic function

\section{Significance Statement}

Mutations in SHANK family genes are causative for idiopathic autism spectrum disorder. To understand the neural function of Shank, a large scaffolding protein enriched at the postsynaptic densities, we examined the role of Drosophila Shank in synapse development at the peripheral neuromuscular junctions and the central mushroom body calyx. Our results demonstrate that, in addition to its conventional postsynaptic function, Shank also acts presynaptically in synapse development in the brain. This study offers novel insights into the synaptic role of Shank.

\section{Introduction}

Accumulating evidence has indicated that mutations in SHANK ( $\mathrm{SH} 3$ domain and ankyrin repeat containing domain) family genes (SHANK1-3) often lead to autism spectrum disorder (ASD) characterized by impaired communication and reciprocal

\footnotetext{
Received March 27, 2017; revised 0ct. 11, 2017; accepted 0ct. 16, 2017.

Author contributions: S.W., R.T., and Y.Q.Z. designed research; S.W., G.G., Z.Z., J.S., Q.W., Z.G., M.L., and R.T. performed research; S.W., S.J., J.H., U.T., Y.J., Y.L., R.T., and Y.Q.Z. analyzed data; S.W., R.T., and Y.Q.Z. wrote the paper.

This work was supported by Ministry of Science and Technology Grant 2014CB942803, Strategic Priority Research Program B of the Chinese Academy of Sciences Grant XDB02020400, and National Science Foundation of China Grants 31110103907 and 31490590 to Y.Q.Z., National Science Foundation of China Grant 31300903 to R.T., Deutsche Forschungsgemeinschaft Grant SFB854-B08 to U.T., and National Institutes of Health Grants MH098114, MH104316, and HD087795 to Y.J. We thank Xiaoming Wang, Zhaohui Wang, and Zhiheng Xu for discussions and comments on the manuscript; Lei Zhang and Peixue Li for providing the UAS-Myc-Shank stock; Troy Littleton for the gift of Shank ${ }^{D 101}$ flies; Jianquan Ni and Xun Huang for assistance in gene targeting; and Bloomington Stock Center, the Vienna Drosophila RNAi Center, Tshinghua RNAi Stock Center, and the Developmental Studies Hybridoma Bank, University of lowa, for fly stocks and antibodies.

The authors declare no competing financial interests.
}

social interactions, and repetitive behaviors. Mutations in SHANK3 were the first (Durand et al., 2007) and remain one of the most replicated and well-characterized SHANK mutations in human ASD. Additionally, the other two members of the SHANK gene family, SHANK1 and SHANK2, have also been associated with ASD (Berkel et al., 2012; Sato et al., 2012), supporting a general function for SHANK proteins in common molecular and neuronal pathways associated with ASD (Grabrucker et al., 2011; Jiang and Ehlers, 2013; Monteiro et al., 2017). Recently, human genetics studies also provide evidence supporting a role of $S H A N K$ family genes in a wide spectrum of other neuropsychiat-

Correspondence should be addressed to either of the following: Dr. Rui Tian or Dr. Yong Q. Zhang, Key Laboratory for Molecular and Developmental Biology, Institute of Genetics and Developmental Biology, Chinese Academy of Sciences, Beijing 100101, China, E-mail: rtian@gentics.ac.cn or yqzhang@genetics.ac.cn.

S. Wu's present address: Tongji Medical College, Huazhong University of Science and Technology, Wuhan 430030, China.

DOI:10.1523/JNEUROSCI.0893-17.2017

Copyright $\odot 2017$ the authors $\quad 0270-6474 / 17 / 3711592-13 \$ 15.00 / 0$ 
ric disorders, including schizophrenia and bipolar disorders (Jiang and Ehlers, 2013; Monteiro et al., 2017). Thus far, mutant mice for each of the three Shank family members have been reported. Analysis of these mutant mice at neuronal, physiological, and behavioral levels has yielded new information on the important role for SHANK family proteins in neuronal development and cognitive function but also show the redundancy among them.

Postsynaptic density (PSD), which is critical for synapse development, function and plasticity, is an electron-dense structure at the excitatory postsynaptic membrane. Shank family members are abundant in the mammalian PSD (Sheng and Kim, 2011), interacting with a list of proteins, including glutamate receptors (GluRs), ion channels, cytoskeletal proteins, scaffolding proteins, enzymes, and signaling proteins via various domains. These domains include an N-terminal ankyrin repeat (ANK), followed by a Src homology 3 (SH3), a PSD-95/Discs large/ZO-1 (PDZ), a proline-rich region (Pro), and a C-terminal sterile $\alpha$ motif (SAM) domain (Naisbitt et al., 1999; Grabrucker et al., 2011). Among the various Shank binding proteins, Homer and Shank form a mesh-like matrix structure and work synergistically for maturation of dendritic spines (Hayashi et al., 2009).

In Drosophila mushroom body (MB) calyces, Kenyon cells (KCs) receive olfactory input from projection neurons (PNs) on their dendrites (Christiansen et al., 2011). The KC dendrites form claw-like ending that enwraps a single PN bouton (Leiss et al., 2009). Several proteins have been shown to localize in the PSDs of the calyx including the scaffold protein Homer, the AChR D $\alpha 7$, the metabotropic glutamate receptor DmGluRA, and the synaptic Dff40/CAD-related protein Drep-2 (Parmentier et al., 1996; Yasuyama et al., 2002; Leiss et al., 2009; Christiansen et al., 2011; Butcher et al., 2012; Andlauer et al., 2014). However, few studies have focused on the role of specific proteins in synapse development and function at the calyx.

To better understand the neuronal functions of Shank, we generated multiple mutations of the only member of the Shank gene family in Drosophila. Shank null mutants showed no apparent morphological and structural defects at neuromuscular junction (NMJ) synapse, which is different from the Shank mutant reported by others recently (Harris et al., 2016). In contrast, the synaptic bouton structures in the calyx as well as calyx-mediated olfactory responses were altered in our Shank mutants. Furthermore, we uncovered a previously unappreciated presynaptic function of Shank protein for normal synaptic connections in the calyx.

\section{Materials and Methods}

Drosophila stocks and husbandry. All fly strains were reared under standard laboratory conditions at $25^{\circ} \mathrm{C}$. The $w^{1118}$ was used as a wild-type control unless otherwise specified. The Shank ${ }^{8 k}$ mutant was generated by the ends-out method (Huang et al., 2009) and deletes an 8210 bp DNA fragment, including exons encoding amino acids (aa) 57-1871 of the longest, 1871 aa Shank. The Shank ${ }^{749}$ mutant was generated by the TALEN method (Liu et al., 2012) and carries a 7 bp frameshift deletion at a position corresponding to aa 749 in the longest Shank. The Shank ${ }^{138}$ mutant was generated by the CRISPR/Cas9 method, carrying a $28 \mathrm{bp}$ DNA deletion at 138 aa of the longest Shank coding starting region (Ren et al., 2013). Shank-gDNA and Shank-GFP were generated on the Shank ${ }^{8 k}$ background using a knock-in method (Huang et al., 2009). The small deficiency of Shank, $D f(2 R) 8328$, was generated through chromosome recombination of two piggyBAC transposons, $P\{X P\} m^{2} m^{d 08375}$ and $P\{X P\}$ Prosap ${ }^{\text {d08828 }} ; D f(2 R) 8328$ deletes the whole genomic sequence of Shank. To overexpress Shank, UAS-Myc-Shank was made by cloning the full-length coding sequence of Shank (GenBank AAF58298.3) into the pUAST-Myc vector. Shank RNAi line Thu2609 was obtained from the
Tsinghua Stock Center. Other stocks included Shank ${ }^{D 101}$ (from T. Littleton, Massachusetts Institute of Technology) (Harris et al., 2016), elav-Gal4 (panneuronal), Repo-Gal4 (glial specific), gh146-Gal4 (PN specific) (Stocker et al., 1997), mb247-Gal4 (MB specific) (Zars, 2010), MB247::D $\alpha 7-G F P$ (labeling the postsynaptic $\mathrm{AChR} D \alpha 7$ subunit under the control of the MB specific MB247 enhancer) (Kremer et al., 2010), and elav-GS-Gal4 (from H. Keshishian, Yale University, New Haven, CT) (Osterwalder et al., 2001).

Generation of rabbit polyclonal anti-Shank antibodies. A cDNA sequence encoding a peptide of aa 807-1000 of the longest Shank (GenBank AAF58298.3) was amplified by PCR and subcloned into the bacterial expression vector pET-28a (Novagen) using the restriction enzymes NheI and NotI. The fusion protein with a $6 \mathrm{xHis}$ tag at the $\mathrm{N}$ terminus of the peptide was used to generate polyclonal antibodies in rabbits. Rabbit sera were affinity purified with the corresponding fusion protein and stored at $\sim 1.5 \mu \mathrm{g}$ protein $/ \mu$ l. Purified polyclonal antibodies were used at 1:200 (fixed with Bouin's solution for $5 \mathrm{~min}$, Invitrogen) and 1:2000 for immunostaining and Western analysis, respectively.

Immunochemical analysis and confocal microscopy. Immunostaining of larval neuromusculatures was performed as previously described (Zhao et al., 2013). Primary antibodies were used as follows: rabbit anti- $\beta$ spectrin (1:1000, RRID:AB_2569853) (Dubreuil and Yu, 1994), anti-CSP (6D6, 1:500, Developmental Studies Hybridoma Bank, RRID:AB_528183), rat anti-GFP (1:500, Kangwei), anti-DLG (1:500, Developmental Studies Hybridoma Bank, RRID:AB_528203), rabbit anti-PAK (1:1000, from L. Zipursky, University of California at Los Angeles), anti-NC82 (1:50, Developmental Studies Hybridoma Bank, RRID:AB_2314866), anti-Elav (1:100, Developmental Studies Hybridoma Bank, RRID:AB_528217), anti-Repo (1:50, Developmental Studies Hybridoma Bank, RRID: AB_90755), rat anti-Homer (1:200, RRID:AB_2567439) (Diagana et al., 2002), and anti-ChAT (1:500, 4B1 from Developmental Studies Hybridoma Bank, RRID:AB_528122). All images were acquired using Olympus BX51 laser scanning confocal microscope with a $40 \times, 1.3$ numerical aperture oil-immersion objective and processed with Adobe Photoshop CS5.

For Western analysis, 60 adult heads of each genotype were dissected and homogenized in ice-cold $120 \mu \mathrm{l}$ RIPA lysis buffer containing $2 \%$ SDS. Lysates from 10 and three heads were loaded in each lane and detected with rabbit anti-Shank at 1:2000 and mouse anti-ChAT at 1:500, respectively. Mouse anti-tubulin (Millipore) was used at 1:50,000 as a loading control. HRP-labeled secondary antibodies against mouse or rabbit IgG (Sigma) were used at 1:50,000. Protein bands were visualized with chemiluminescent HRP substrate (Millipore).

Electrophysiology. Excitatory junction potentials (EJPs) and spontaneous miniature EJPs (mEJPs) at NMJs were recorded using intracellular electrodes (Zhao et al., 2013). Briefly, wandering third instar larvae were dissected in $\mathrm{Ca}^{2+}$-free HL3 saline $(70 \mathrm{~mm} \mathrm{NaCl}, 5 \mathrm{~mm} \mathrm{KCl}, 20 \mathrm{~mm}$ $\mathrm{MgCl}_{2}, 10 \mathrm{~mm} \mathrm{NaHCO} 3,115 \mathrm{~mm}$ sucrose, $5 \mathrm{~mm}$ trehalose, $5 \mathrm{~mm}$ HEPES, $\mathrm{pH}$ 7.3). Both EJPs and mEJPs were recorded from muscle 6 of abdominal segment A2 or A3 in HL3 saline containing 0.4 and $1.0 \mathrm{~mm} \mathrm{Ca}^{2+}$ using intracellular microelectrodes $(10-20 \mathrm{M} \Omega$ ) filled with $3 \mathrm{~m} \mathrm{KCl}$. EJPs were evoked at $0.3 \mathrm{~Hz}$ by a suction electrode using a depolarizing pulse delivered by a Grass S48 stimulator (Astro-Grass Instruments). A total of $18-25$ EJPs were recorded from at least 10 individual animals, followed by $\mathrm{mEJP}$ recording for $120 \mathrm{~s}$. All electrophysiological responses were recorded using Axoclamp 2B amplifier (Molecular Devices) in Bridge mode and analyzed using Clampfit 10.2 software. Only recordings from cells with resting potentials $\leq-60 \mathrm{mV}$ and input resistances $>6 \mathrm{M} \Omega$ were analyzed according to Martin's equation.

Electron microscopy (EM). EM of larvae NMJs was performed as described previously (Zhao et al., 2013). EM analysis of adult MB calyces was performed according to published protocols with minor modification (Leiss et al., 2009; Butcher et al., 2012). Briefly, fly heads of 4- to 6-d-old females were dissected and fixed at $4^{\circ} \mathrm{C}$ for $4 \mathrm{~h}$ in $0.1 \mathrm{M}$ PBS buffer, pH 7.4, with 2.0\% PFA and 2.0\% glutaraldehyde (v/v). The fixed samples were then washed and postfixed with $1 \%$ osmium tetroxide at $4^{\circ} \mathrm{C}$ for $2 \mathrm{~h}$. Staining with uranyl acetate, dehydration, and infiltration with resin were performed according to standard protocols. Semithin $1-2 \mu \mathrm{m}$ sections were cut in a tangential plane from the posterodorsal surface of the head until they contained the cortex of KC bodies overlay- 
ing the MB calyx. Ultrathin sectioning at $70 \mathrm{~nm}$ per slice then advanced slowly through to the distal surface of the calyx. Projection neuron terminal boutons were identified by their size (larger than other elements) and by the features of active zones (Yasuyama et al., 2002). As microglomeruli in horizontal sections of each genotype show similar profiles of axon fibers and terminals, the region containing mostly axon terminals was chosen for statistical analysis.

Behavioral and cognitive assays. All flies used for behavioral experiments were outcrossed to isogenized Canton-S (CS) for more than five generations to clear their genetic background. Climbing ability was assayed according to a previously published protocol with minor modifications (Palladino et al., 2002). Twenty male flies, 4- to 6-d-old, of a specific genotype were randomly selected and transferred to a new vial $2 \mathrm{~d}$ before use. Flies were placed in a 3.5 -cm-diameter, 30-cm-length cylinder that was sealed with gauze at the top to prevent escape. The flies were gently knocked down to the bottom of the cylinder, and the time required for $50 \%$ of the flies to cross the $15 \mathrm{~cm}$ line was recorded. Three trials without interval were performed for each sample, and the average time from three trials was used for statistical analysis.

Learning and memory tests were conducted according to the classical conditioning procedure (Tully and Quinn, 1985). A group of $\sim 1002$ - to 5-d-old adult flies were assayed given 2 min choosing time; 10-12 groups were analyzed for each genotype, with each group tested one time. The learning index enumerates the distribution of flies in the T-maze as a normalized "percent correctly avoiding the shock-paired odor" and the range from 0 for a 50:50 distribution to 100 for a 100:0 distribution.

Olfactory acuity was measured as odor avoidance and was quantified by placing a group of $\sim 100$ of 2 - to 5 -d old adult flies in a T-maze where they had a choice for 2 min between aversive odor of either 4-methylcyclohexanol $(\mathrm{MCH})$ or 3-octanol $(\mathrm{OCT})$ and air. Odor acuity index = $(N[$ air $]-N[$ odor $]) /(N[$ odor $]+N[$ air $]), N[$ odor $]$ and $N[$ air] are numbers of flies choosing odor (MCH or OCT) and air, respectively. To test shock avoidance, $\sim 100$ flies of 2 - to 5 -d old in a T-maze were given the choice for 2 min between an electrified grid in one arm and a nonelectrified grid in the other. After the flies had distributed to either arm for 2 $\mathrm{min}$, they were collected and counted. Electric avoidance index $=(N[\mathrm{c}]-$ $N[\mathrm{e}]) /(N[\mathrm{e}]+N[\mathrm{c}]) ; N[\mathrm{e}]$ and $N[\mathrm{c}]$ are numbers of flies choosing electrified and nonelectrified arms, respectively.

Statistical analysis. All statistical analysis was performed using either Student's $t$ test for comparison of 2 group means or ANOVA for comparison of multiple group means by Tukey's test for post hoc comparison. Data are presented as mean \pm SEM.

\section{Results}

\section{Drosophila genome encodes a single member of the Shank protein family}

The Shank protein family is well conserved from Caenorhabditis elegans to humans. Instead of three independent genes encoding Shank protein family members (SHANK1-3) in mammals, the Drosophila genome contains only one Shank gene (Harris et al., 2016), so does the C. elegans genome (Jee et al., 2004). To date, no apparent Shank homolog has been identified in the yeast genome. There are four predicted Drosophila Shank splice variants all comprising the C-terminal 1660 to 1871 aa (http://flybase.org/ reports/FBgn0040752.html). Sequence comparison between the longest Drosophila Shank (1871 aa) and human SHANK3 revealed conserved protein domain organization (56\% identity and $74 \%$ similarity for the ANK domain, 34\% identity and 63\% similarity for the SH3 domain, and 47\% identity and 64\% similarity for the PDZ domain) (Fig. 1A), although the overall homology is relatively low (23\% identity and 38\% similarity). Drosophila Shank was also shown to contain a conserved proline-rich region, containing multiple glutamine (Q)-rich stretches, but did not have an identifiable SAM domain at the C-terminal (Fig. 1A).

To understand the in vivo functions of Shank protein, we generated several deletions for the Shank gene using various approaches (Fig. 1B). Drosophila Shank has 13 exons that encode a full-length protein of 1871 aa. Shank ${ }^{8 k}$ was generated by deleting an 8210 bp DNA fragment containing exons 4-12 that encode protein from 57 to 1871 aa of the longest Shank (Fig. 1B). Shank $k^{749}$ mutant carried a deletion of $7 \mathrm{bp}$ within the exon 10 , whereas Shank ${ }^{138}$ mutant had a 28 bp deletion in exon 5, both of which resulted in a frameshift at the N-terminal that affected all known Shank isoforms (Fig. 1B). Thus, all three mutations probably resulted in null alleles at molecular level. All three Shank mutant alleles were fully viable and fertile without apparent morphological or developmental abnormalities. For the majority of experiments described below, we focused on Shank ${ }^{8 k}$, but others were included for certain experiments. For genomic rescue experiments, we generated Shank-gDNA, in which the deleted Shank genomic DNA was reinserted back into the Shank ${ }^{8 k}$ founder allele and expresses wild-type Shank. To study the endogenous Shank expression pattern, we constructed Shank-GFP, which expresses GFP tagged full-length Shank fusion protein under the control of the endogenous Shank promoter (Fig. 1B). A $U A S-M y c-S h a n k$ line was also produced for neuron-type specific rescue experiments. All deletions and transgenic lines were verified by DNA sequencing and protein analysis using a rabbit polyclonal antibody recognizing the epitope within the proline-rich region of Shank protein (Fig. $1 A, C$ ).

\section{Shank mutants show normal NMJ structure}

Shanks are synaptic scaffolding proteins that organize an extensive protein complex at the PSD of excitatory synapses (Jiang and Ehlers, 2013). Drosophila NMJ synapses use ionotropic GluRs that are homologous to mammalian AMPA-type GluRs and kainate receptors, and thus offer an attractive model for study of excitatory synapses in the mammalian CNS (Collins and DiAntonio, 2007). To test whether Shank plays a role at NMJs, we examined its expression by immunostaining and found weak expression at NMJs (Fig. 2A). Anti-GFP staining of the ShankGFP knock-in line showed that Shank was localized at axons and presynaptic, but not postsynaptic, sites of the NMJs. Immunostaining results of larvae expressing Shank-GFP with anti-GFP were consistent with the expression of the endogenous Shank (Fig. 2A,B). SAM domain is implicated in postsynaptic targeting in mammals (Boeckers et al., 2005). The absence of a SAM domain in Drosophila Shank may partially explain the distinct localizations between Drosophila and mammalian Shank. To uncover a potential role of Shank at NMJ synapses, we examined the expression level and localization of synaptic proteins, such as CSP, DLG, $\beta$-spectrin, and PAK by immunostaining (Fig. $2 C$ ) and also assessed the ultrastructure of NMJ boutons by EM (Fig. 2D). Shank $^{8 k}$ mutants showed normal NMJ morphology and PSD structures at both light and EM level (Fig. 2C,D).

To determine whether synaptic transmission was impaired in Shank mutants, we performed classical intracellular recordings of the NMJ 6/7 at abdominal segments A2 or A3 of wandering third instar larvae at different calcium concentrations. Our results showed that the mEJP amplitudes of Shank mutants were not altered compared with wild-type controls at $0.4 \mathrm{mM} \mathrm{Ca}^{2+}(0.890 \pm 0.054 \mathrm{mV}$ in wild-type vs $0.910 \pm 0.037 \mathrm{mV}$ in Shank ${ }^{749}$, and $0.947 \pm 0.038 \mathrm{mV}$ in Shank ${ }^{8 k} ; p=0.053$ for Shank $k^{749}$ and $p=0.382$ for Shank $^{8 k}$; Fig. $2 E, F)$. The EJP amplitudes were also not altered in Shank mutants at $0.4 \mathrm{mM} \mathrm{Ca}^{2+}(11.71 \pm 0.76 \mathrm{mV}$ in wild-type vs $11.42 \pm$ $0.91 \mathrm{mV}$ in Shank $k^{749}$, and $11.72 \pm 1.31 \mathrm{mV}$ in Shank ${ }^{8 k ;} p=0.405$ for Shank $k^{749}$ and $p=0.497$ for Shank ${ }^{8 k}$; Fig. $2 H$ ). However, mEJP frequency was significantly increased in Shank ${ }^{8 k}$ mutants at 0.4 $\mathrm{mM} \mathrm{Ca}^{2+}(2.83 \pm 0.27 \mathrm{~Hz}$ in wild-type vs $3.40 \pm 0.17 \mathrm{~Hz}$ in Shank $^{749}, p=0.082$ and $4.20 \pm 0.26 \mathrm{~Hz}$ in Shank ${ }^{8 k}, p<0.001$; Fig. 


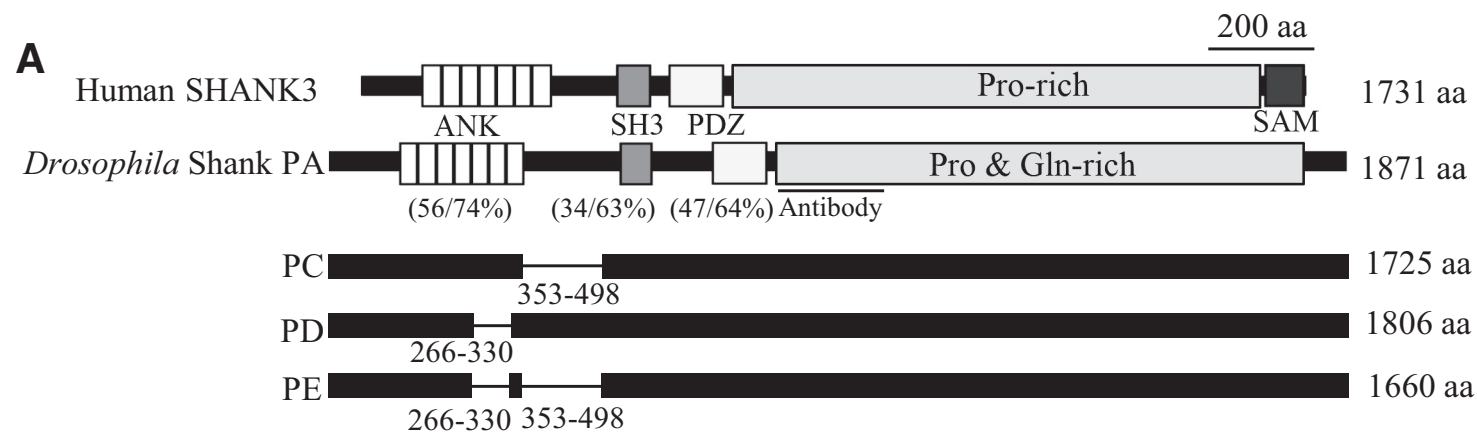

B

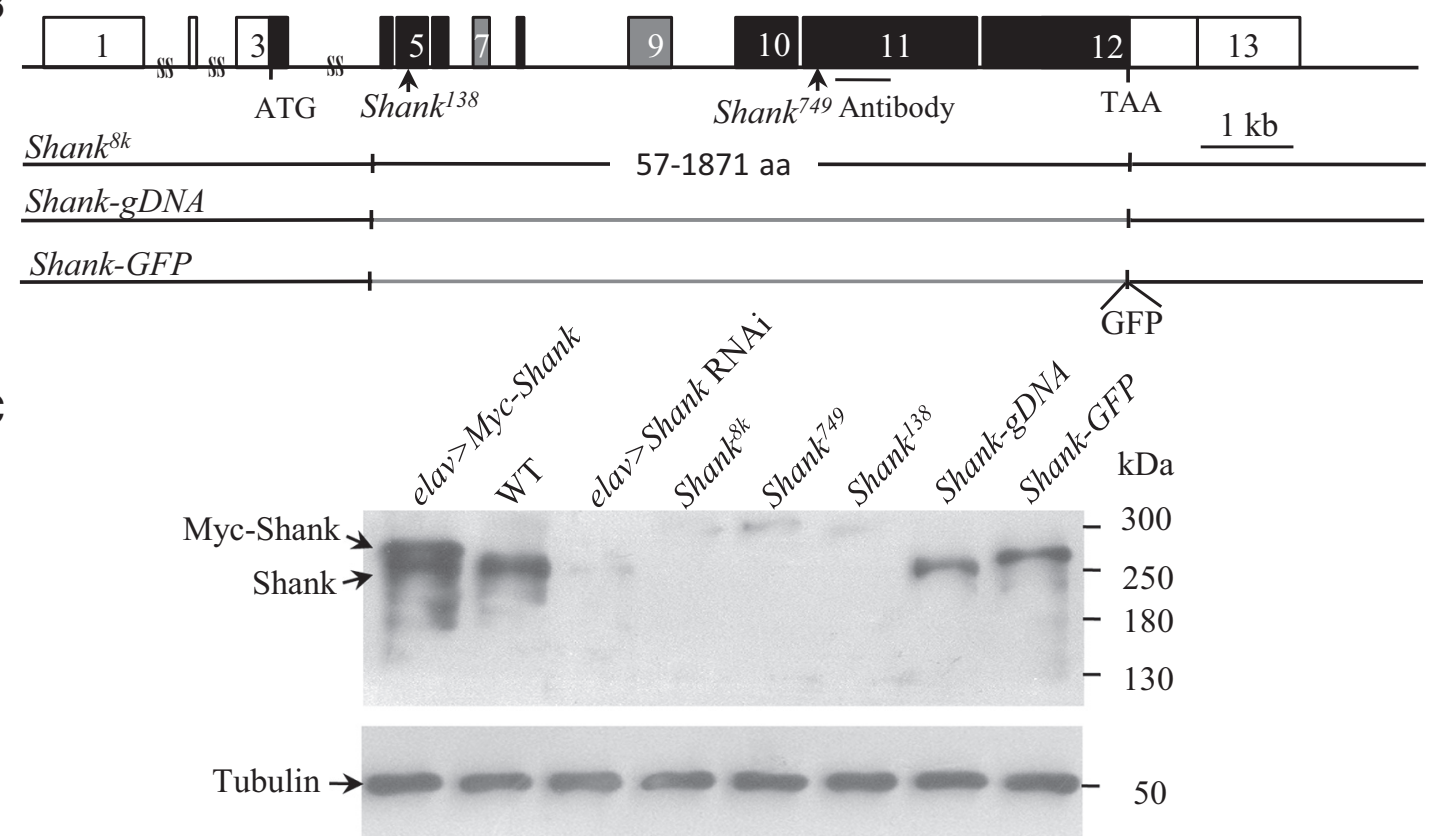

Figure 1. Characterization of Shank mutant alleles. A, Domain structure of human SHANK3 (NP_277052.1) and four Drosophila Shank (CG30483) isoforms. Rabbit anti-Shank polyclonal antibody recognizing Drosophila Shank 807-1000 aa is indicated. Percentages below the domains indicate identity/similarity between Drosophila Shank and human SHANK3. Bar represents 200 aa. $\boldsymbol{B}$, Genomic structure and mutant alleles of Shank. Boxes represent exons, which are numbered from 1 to 13 . Black boxes represent coding regions. Gray represents alternatively spliced exons. Translation start codon ATG and stop codon TAA are denoted. SS indicates regions that are not depicted to scale. Bar represents $1 \mathrm{~kb}$ pairs. Two small deletions that result in Shank frameshift mutations at 138 aa and 749 aa affecting all Shank isoforms are indicated as Shank ${ }^{138}$ and Shank $k^{749}$. Shank ${ }^{8 k}$ mutants were generated by deleting a large portion of the coding sequence (exons $4-12$ ) of Shank. Shank-GFP and Shank-gDNA are genomic knock-ins on the Shank ${ }^{8 k}$ background with and without a GFP tag at the C-terminal, respectively. C, Western blot analysis of adult brains from different Shank mutants. Adult brains expressing Myc-Shank driven by elav-Gal4 (elav > Myc-Shank) exhibited a Myc-tagged fusion protein as well as endogenous protein. Neuronal specific knockdown of Shank driven by elav-Gal4 (elav > Shank RNAi) showed a very weak Shank band. Tubulin is used as a loading control.

$2 E, G)$. At $1.0 \mathrm{mM} \mathrm{Ca}^{2+}$ concentration, the mEJP and EJP amplitudes remained normal, whereas mEJP frequency showed a similar increase in Shank mutants as it did at $0.4 \mathrm{mM} \mathrm{Ca}^{2+}(3.02 \pm$ $0.19 \mathrm{~Hz}$ in wild-type vs $3.31 \pm 0.22 \mathrm{~Hz}$ in Shank ${ }^{749}, p=0.094$ and $3.55 \pm 0.21 \mathrm{~Hz}$ in Shank $\left.{ }^{8 k}, p=0.0189\right)$. These results show that Shank mutants have normal evoked neurotransmission but increased frequency of spontaneous transmission at NMJ synapses, suggesting that Shank may function at the presynaptic terminus directly or indirectly.

\section{Shank is widely expressed in the CNS and highly enriched in neuropil}

Shanks are expressed in the murine brain in various spatiotemporal patterns. Specifically, Shank1 is expressed throughout most of the brain, and in particular, the cerebral cortex and hippocampus (Lim et al., 1999). Shank2 is also broadly expressed in the brain, with a higher expression in cerebellar Purkinje cells (Boeckers et al., 1999; Schmeisser et al., 2012), whereas Shank3 is highly ex- pressed in striatum, neocortex, thalamus, and cerebellar granule cells (Boeckers et al., 1999; Schmeisser et al., 2012).

We examined Drosophila Shank expression patterns in the CNS and found that Shank was enriched in the neuropil regions, where the active zone marker protein Bruchpilot (anti-NC82) is highly expressed (Fig. 3A), and detectable in the soma of a substantial population of central neurons labeled by Elav, a panneuronal marker (Fig. 3B). Moreover, Shank was also expressed in different types of glial cell as indicated by Repo expression, including midline glia, surface glia, and cortex glia (Fig. 3C), indicating that the expression of Shank is not restricted to neurons in the brain.

Similar to the vertebrate Shank proteins, Drosophila Shank contains a Homer-binding consensus motif PPxxF near its $\mathrm{C}$ terminus. An interaction of Drosophila Shank and Homer was first identified by a yeast two-hybrid screen (Diagana et al., 2002). Same as Shank mutants, Homer mutants are also fully viable and fertile without apparent morphological or developmental abnor- 
A

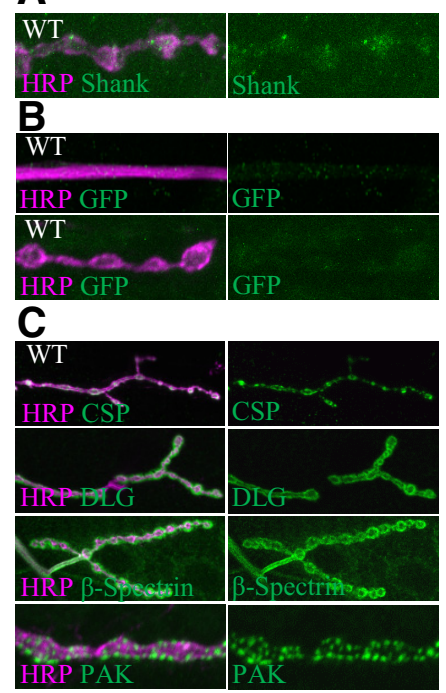

E

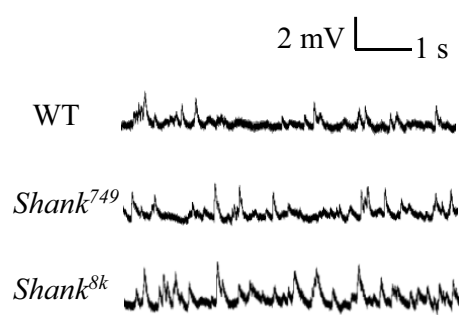

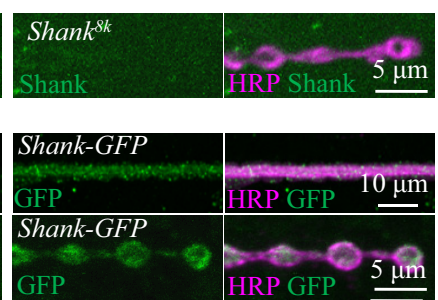

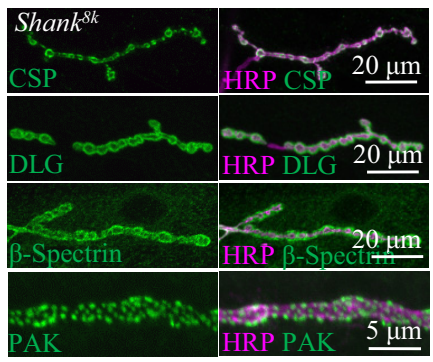

$\mathbf{F}$

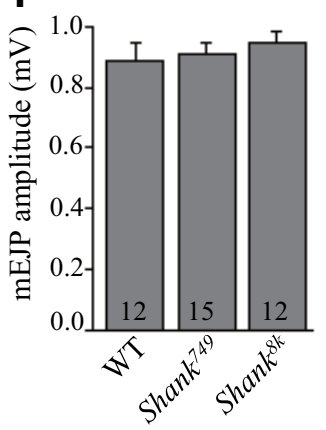

G
D
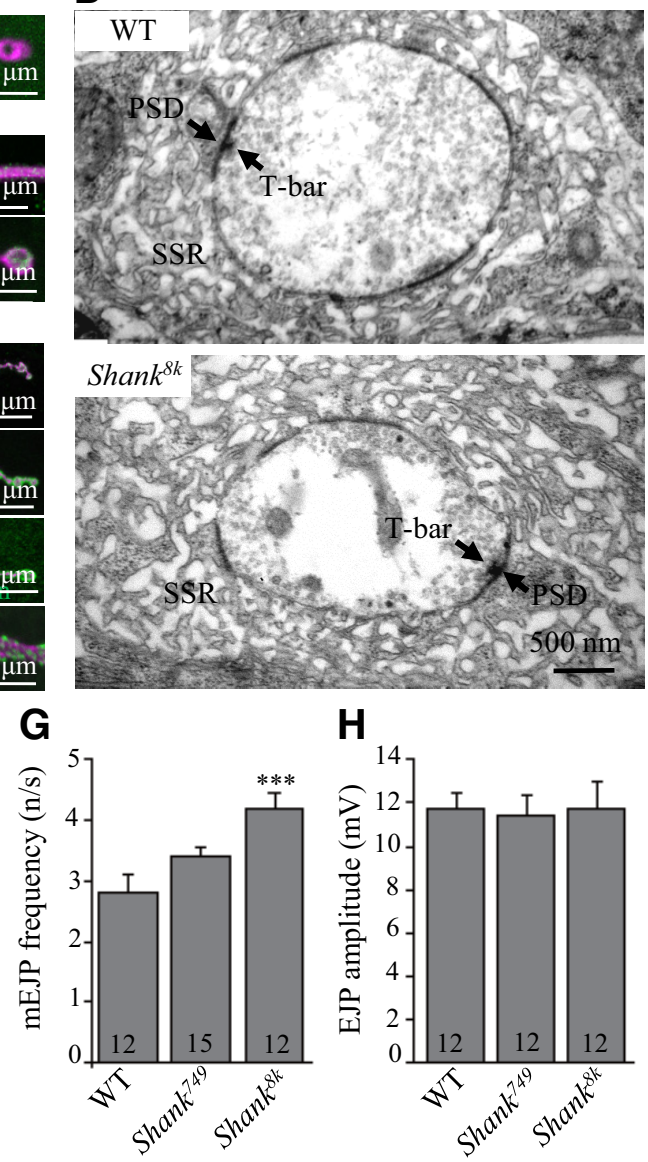

H

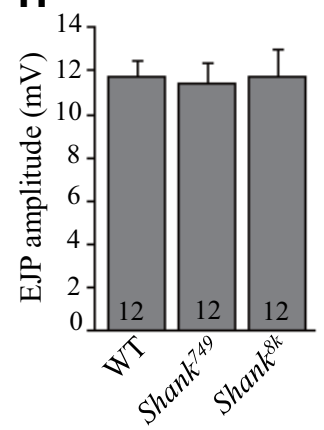

Figure 2. No NMJ structural defects are apparent in Shank mutants. $\boldsymbol{A}-\boldsymbol{C}, \boldsymbol{Z}$-stack confocal images. $\boldsymbol{A}$, Double-staining of NMJs with anti-Shank (green) and the neuronal membrane marker anti-HRP (magenta) showed weak presynaptic Shank staining at the NMJ. B, Knock-in of Shank-GFP as assessed by anti-GFP (green) showed Shank expression in axons and presynaptic boutons of NMJs. C, Localization of synaptic markers, such as CSP, DLG, $\beta$-spectrin, and PAK, appeared normal at the NMJ boutons of Shank ${ }^{8 k}$ mutants. $D$, The ultrastructures of NMJs appear normal in Shank mutants. The PSD, subsynaptic reticulum (SSR), and T-bar are indicated. Scale bar, $500 \mathrm{~nm}$. $\boldsymbol{E}$, mEJP traces of NMJ terminals at $0.4 \mathrm{~mm} \mathrm{Ca}^{2+}$ from different genotypes. Scales are indicated. $\boldsymbol{F}-\boldsymbol{H}$, Statistical results of mEJP amplitude $(\boldsymbol{F})$, mEJP frequency $(\boldsymbol{G})$, and EJP amplitude $(\boldsymbol{H})$ from different genotypes. $n=18 .{ }^{*} p<0.05,{ }^{* *} p<0.01$. Error bars indicate SEM.

malities (Diagana et al., 2002). In Drosophila, Homer is highly expressed in the CNS and enriched in the PSD of MB calyx (Andlauer et al., 2014). As shown in Figure 3D, E, Shank and Homer were coexpressed in the larval brain and ventral nerve cord and particularly enriched in the MB calyx (Fig. 3D) and ventral nerve cord neuropil (Fig. 3E), supporting that Drosophila Shank is also enriched at the PSD of the CNS.

\section{Developmental defects of synapse in the larval calyx of}

\section{Shank mutants}

The calyx constitutes the second olfactory center in Drosophila. Odors are detected through olfactory sensory neurons and are processed within antennal lobes acting as the primary olfactory centers. Subsequently, olfactory information is conveyed to the calyx via olfactory PNs (Christiansen et al., 2011; Li et al., 2013). PNs target two separate neuropils, the $\mathrm{MB}$ and the lateral horn (Butcher et al., 2012; Li et al., 2013) (Fig. 4A). PNs contact KCs at glomeruli in the larval brain (Masuda-Nakagawa et al., 2005) and microglomeruli in the adult brain (Yasuyama et al., 2002). The larval calyx is composed of at least 34 glomeruli (MasudaNakagawa et al., 2005), whereas the adult calyx comprises hundreds of microglomeruli (Yasuyama et al., 2002). As Shank is expressed in the PSDs in the calyx, we predicted that Shank mutants might exhibit structural defects in the synaptic boutons of the calyx. ChAT labels presynaptic boutons of PN termini in the calyx (Yasuyama et al., 2002; Leiss et al., 2009; Butcher et al., 2012). ChAT staining of a wild-type larval brain revealed evenly distributed ChAT-positive puncta within glomeruli with multiple protrusions (Fig. $4 B, E$ ). The protrusions marked by ChATpositive puncta were lost and instead fused together to form smaller, unilobed glomeruli in Shank ${ }^{8 k}$ mutants. We manually quantified ChAT-positive protrusions at the edge of each glomerulus. Three distinct glomeruli from each calyx of six larvae were statistically analyzed for each genotype. Homozygous Shank ${ }^{8 k}$ mutants showed a dramatically reduced number of protrusions $(1.17 \pm 0.21$ vs $10.78 \pm 0.53$ in controls, $p<0.001)$, so did homozygous Shank ${ }^{D 101}$, trans-allelic Shank ${ }^{8 k / D 101}$, and hemizygous Shank ${ }^{8 k} / D f(2 R) 8328$ and Shank $k^{D 101} / D f(2 R) 8328$ mutants (Fig. $4 B, E)$. Shank $k^{8 k} /+$ and Shank $k^{D 101} /+$ heterozygous mutants also showed similar but weaker calyx defects compared with homozygous mutants (Fig. 4B,E), and the reduced numbers of ChATpositive protrusions in Shank mutants were fully rescued by genomic knock-in of Shank (Shank-gDNA) as well as by elavGal4-driven expression of Myc-Shank (10.78 \pm 0.53 in controls vs $10.33 \pm 0.34$ for Shank-gDNA and $11.00 \pm 041$ for Myc-Shank rescue; Fig. $4 B, E$ ). Together, these results demonstrate that Shank regulates synapse development in the larval calyx. 
A
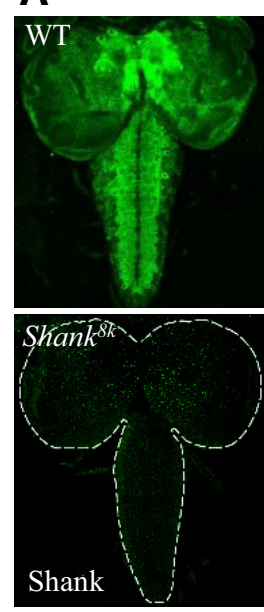

D
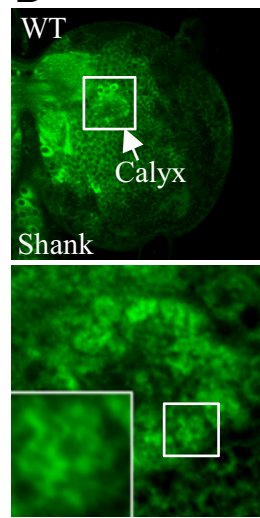
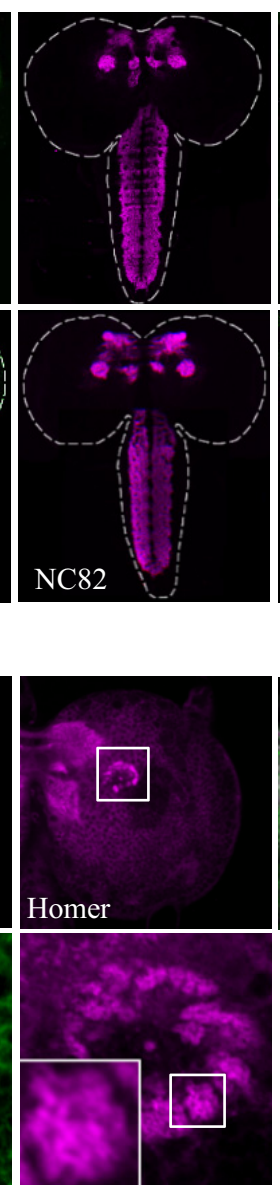
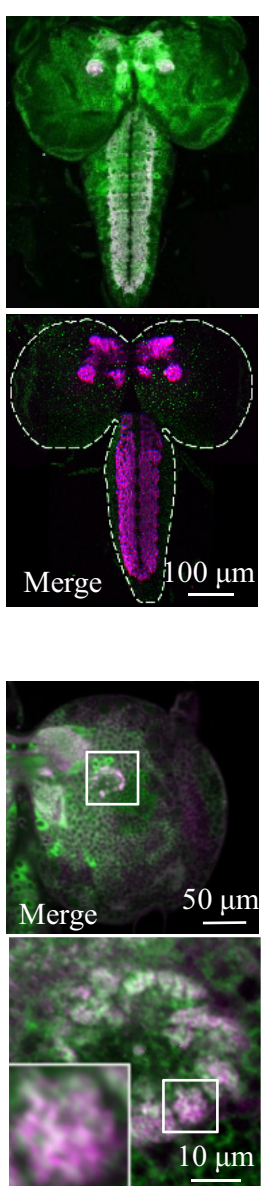

B
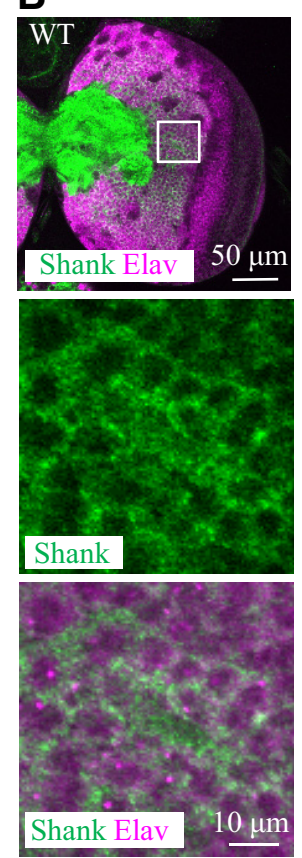

E

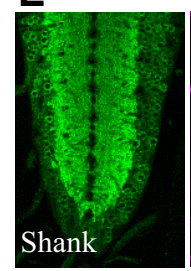

C
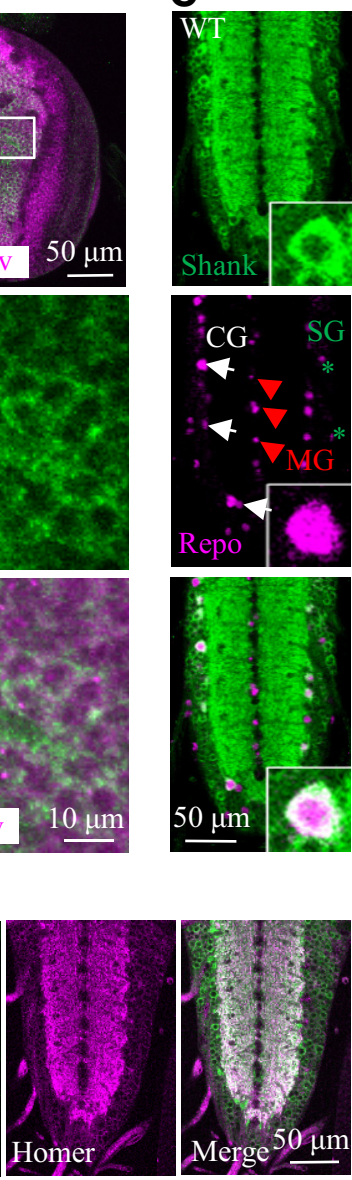

Figure 3. Endogenous Shank is highly expressed in the neuropil of the larval CNS. $\boldsymbol{A}-\boldsymbol{E}$, Single slice confocal images. $\boldsymbol{A}$, Images of third instar larval brain double-stained with anti-Shank (magenta) and anti-NC82 (green; a presynaptic marker). Scale bar, $100 \mu \mathrm{m}$. B, Double immunostaining of larval CNS with anti-Shank and a pan-neural marker anti-Elav showed Shank expression in most neurons. C, Shank is expressed in a subset of glial cells, including cortex glia (CG, arrows). The ventral nerve cord (VNC) was double-stained with anti-Shank (magenta) and the glial marker anti-Repo (green). MG, Midline glia (arrowheads); SG, surface glia (asterisks). Scale bar, $50 \mu \mathrm{m}$. D, Shank and Homer are highly enriched and coexpressed in the calyx (outlined). E, Shank and Homer are coexpressed at the neuropil of larval VNC. Scale bar, $50 \mu \mathrm{m}$.

Shank has both presynaptic and postsynaptic functions in the larval MB calyx

Although most studies have indicated an essential role for Shank in mammalian PSD at postsynaptic sites (Jiang and Ehlers, 2013; Monteiro et al., 2017), several others have provided experimental evidence suggesting that Shank is involved in a variety of functions outside of PSD, including axonal outgrowth, growth cone mobility, and presynaptic specializations in mammals (Du et al., 1998; Durand et al., 2012; Halbedl et al., 2016). To determine whether the abnormal synapse development of Shank mutants was caused by alterations in either presynaptic or postsynaptic function or both, neuron-type specific rescue experiments were performed. gh146-Gal4, which is specifically expressed in PN neurons, was used to drive presynaptic expression, whereas mb247-Gal4, which is MB specific, was used to drive postsynaptic expression at PN/KC connection sites. Both Gal4 lines drove a substantial expression of Shank as expected (Fig. 4C). Protrusion numbers were significantly higher in gh146-Gal4-driven reexpression of Shank compared with Shank ${ }^{8 k}$ mutants, indicating a presynaptic role for Shank (5.39 \pm 0.25 in gh146-Gal4 rescue and $1.17 \pm 0.21$ in Shank $\left.{ }^{8 k}, p<0.001\right)$. We note that the presynaptic expression of Shank only partially rescued the protrusion phenotypes of Shank ${ }^{8 k}$ mutants (Fig. $4 C, E$ ). In contrast, there was no rescue of the protrusion phenotype by postsynaptic expression, as there was no significant difference in the number of protrusions between $m b 247-G a l 4$-driven reexpression and Shank ${ }^{8 k}$ mutants $(1.72 \pm 0.25$ vs $1.17 \pm 0.21, p=0.120$ ) (Fig. $4 C, E$ ). We also performed rescue experiments with double Gal4 lines mb247Gal4 and gh146-Gal4, which produced a stronger rescue effect compared with gh146-Gal4 alone (7.94 \pm 0.82 vs $5.39 \pm 0.25, p=$ 0.011 ) (Fig. $4 C, E$ ). Thus, a presynaptic function of Shank seems to be essential, whereas postsynaptic Shank contributes to the normal synaptic contacts at the MB calyx.

To determine whether pan-neuronal expression of Shank by elav-Gal4 in late stages could also rescue the Shank mutant phenotype, the gene switch method was used. This method uses RU486 to induce target gene expression, and protein expression can be detected as early as $5 \mathrm{~h}$ after induction (Osterwalder et al., 2001). The synapse defects in the glomeruli of Shank ${ }^{8 k}$ mutants were fully rescued upon RU486-induced expression of Shank for 2 or $3 \mathrm{~d}$ (Fig. $4 D, E$ ). The number of protrusions surrounding each glomerulus was $10.61 \pm 0.52$ in wild-type, and $2.94 \pm 0.32$ in Shank ${ }^{8 k}$ mutants without induced expression of Shank $(p<0.001)$, but $9.39 \pm 0.31$ and $10.67 \pm 0.23$ in Shank ${ }^{8 k}$ mutants after induced expression of Shank for 2 and $3 \mathrm{~d}$, respectively. 
A

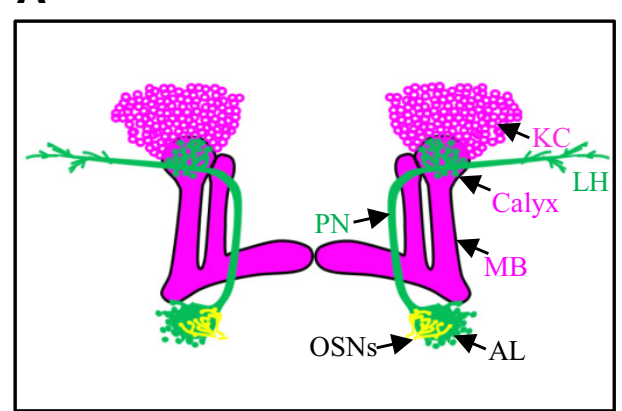

\section{C}
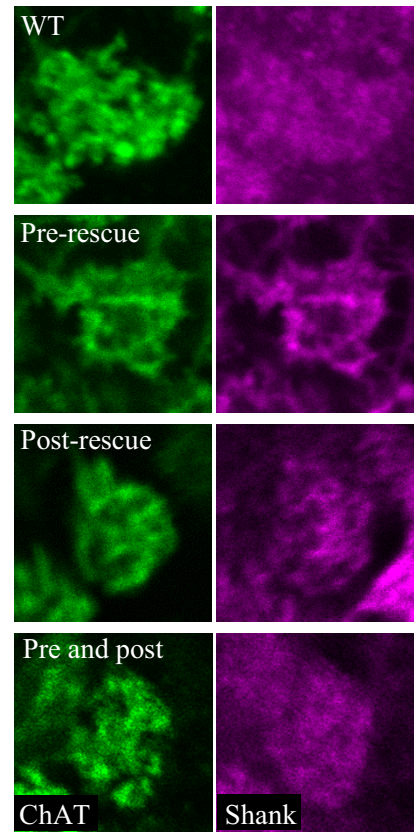

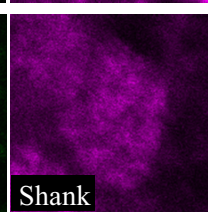

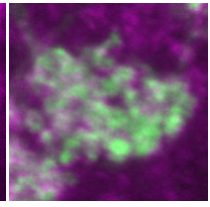
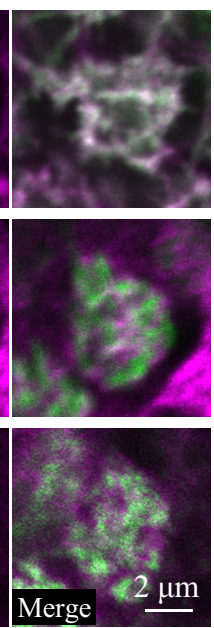

B
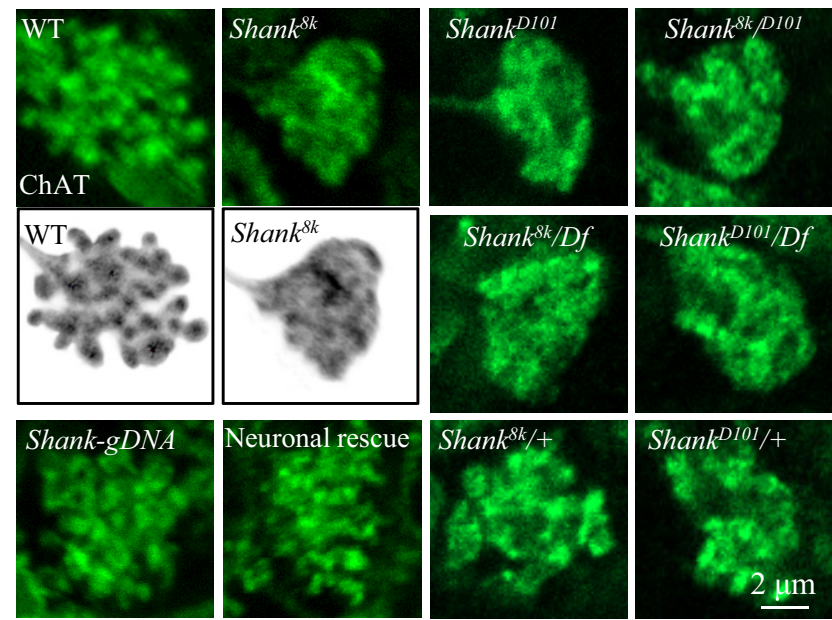

D

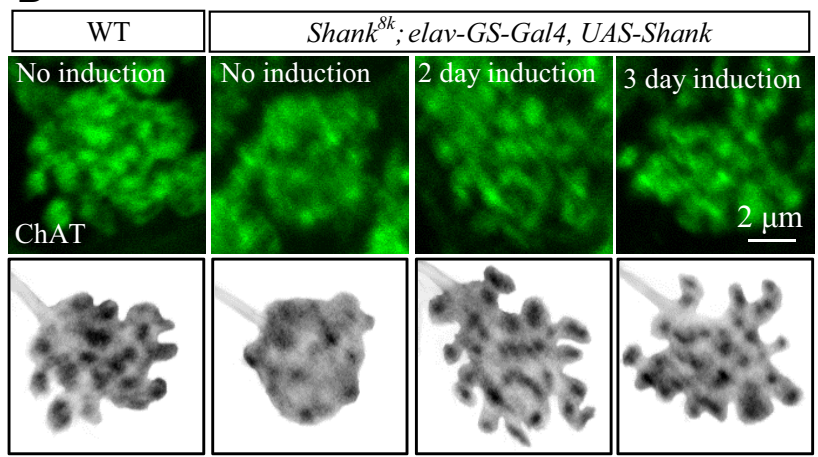

$\mathbf{E}$

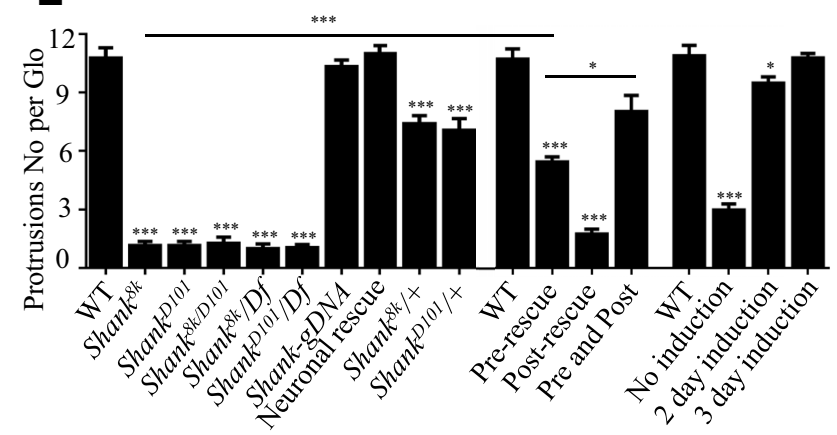

Figure 4. Presynaptic Shank is necessary for normal synapse formation in the larval calyx. $A$, A schematic diagram of larval olfactory circuit. AL, Antenna lobe; OSN, olfactory sensory neuron; PN, projection neuron. $\boldsymbol{B}-\boldsymbol{D}, \boldsymbol{z}$-stack confocal images. $\boldsymbol{B}$, In the calyx of wild-type controls, glomeruli contained evenly distributed, ChAT-positive puncta with multiple protrusions. In Shan ${ }^{8 k}$, Shank ${ }^{D 101}$, Shank $k^{8 k / 101}$, Shank $k^{8 k} / D f(2 R) 8328$, and Shank ${ }^{D 101} / D f(2 R) 8328$ mutants, glomeruli were unilobed with no apparent protrusions. Heterozygous Shank ${ }^{8 k} /+$ and Shank ${ }^{D 101} /+$ mutants also showed weak but significant reduction of protrusion numbers compared with wild-type. These defects were rescued by Shank genomic knock-in (Shank-gDNA) or pan-neuronal expression of Shank (elav-Gal4/+; Shank ${ }^{8 k}$; UAS-Myc-Shank/+). Scale bar, $2 \mu \mathrm{m}$. Schematic depictions of the glomeruli in wild type and Shank ${ }^{8 k}$ mutants are shown. C, Double staining of the calyx with anti-ChAT (green) and anti-Shank (magenta). Presynaptic expression of Shank by gh146-Gal4 partially rescued the unilobed glomerulus phenotype in Shank $k^{8 k}$ mutants, whereas postsynaptic expression of Shank driven by mb247-Gal4 showed no rescue. Both presynaptic and postsynaptic expression of Shank by the double Gal4 lines mb247-Gal4 and gh 146 -Gal4 produced a stronger rescue effect than that by gh 146-Gal4 alone. $\boldsymbol{D}$, The unilobed glomeruli of Shank mutants were rescued by pan-neuronal expression of Shank at later larval stages. RU486 was added to the food at a final concentration $2 \mu \mathrm{g} / \mathrm{ml}$ at day 0 , day 2 , and day 3 before dissection at late third instar larvae to induce expression of Shank. Bottom, Schematic depiction of the glomeruli in different treatments. $E$, Statistical results of protrusion number for each glomerulus in different genotypes. $n=18 .{ }^{*} p<0.05$, ${ }^{* * *} p<0.001$.

Developmental defects of synapses in the adult calyx of Shank mutants

To determine whether synapse defects were also present in adult calyces that undergo remodeling during metamorphosis, we examined adult calyces in different Shank alleles by anti-ChAT staining and conducted rescue experiments (Fig. $5 \mathrm{~A}$ ). We manually quantified the number of ChAT-positive puncta in a $20 \times 20 \mu \mathrm{m}^{2}$ area of calyx surface from six adult brains. All independent Shank mutant alleles, Shank ${ }^{8 k}$, Shank ${ }^{138}$, and Shank ${ }^{749}$ exhibited similar defective boutons. The number of ChAT-positive puncta per $20 \times 20 \mu \mathrm{m}^{2}$ area of the calyx were $44.83 \pm 2.14$ in wild-type, $16.67 \pm 0.61$ in Shank $^{8 k}, 11.17 \pm 0.65$ in Shank ${ }^{749}$, and $10.83 \pm 0.70$ in Shank ${ }^{138}(p<$ 0.001 for all 3 mutant alleles; Fig. $5 B$ ). Notably, Western blot analysis demonstrated that the total level of ChAT protein was not altered in Shank mutants (Fig. 5C). The reduced number of anti-ChAT puncta of Shank ${ }^{8 k}$ was fully rescued by genomic knock-in of Shank-gDNA and elav-Gal4-driven expression of Shank ( $p>0.05$ for both genotypes compared with wild-type; Fig. $5 A, B$ ). 
A
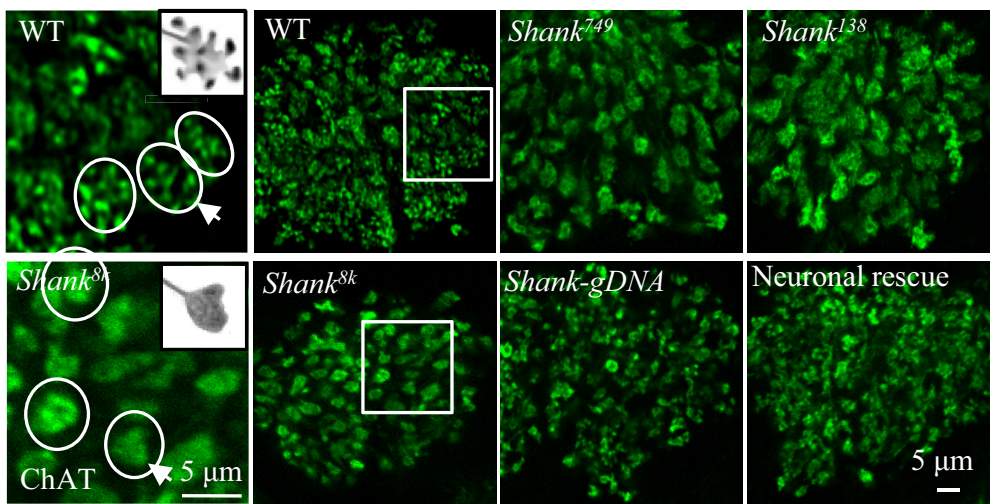

D
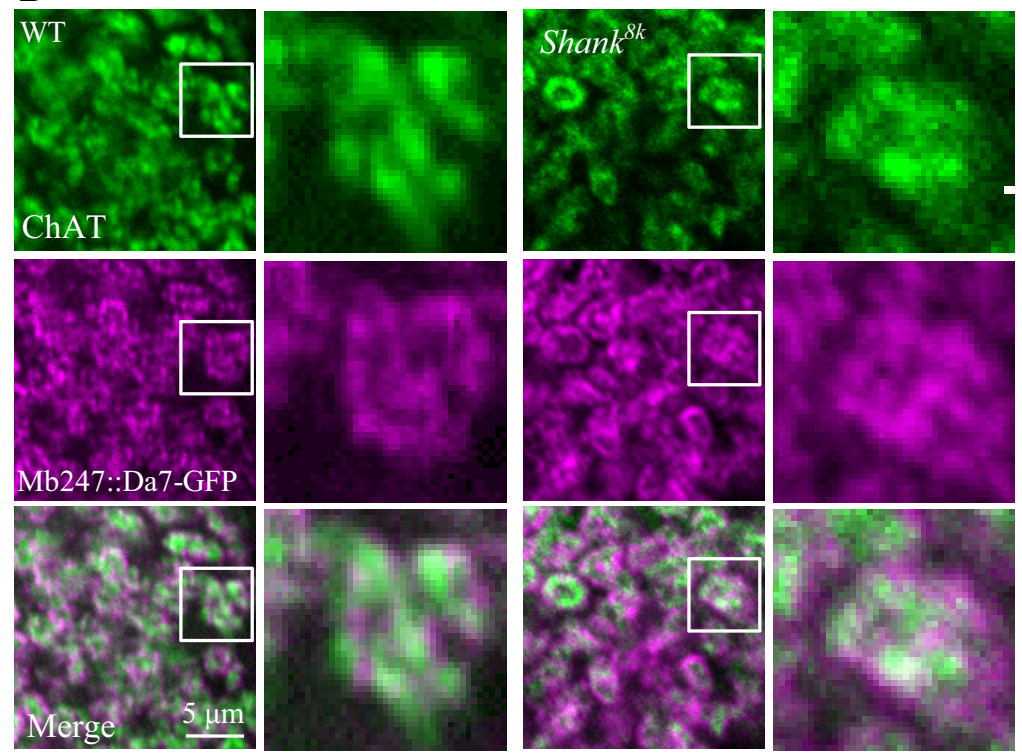
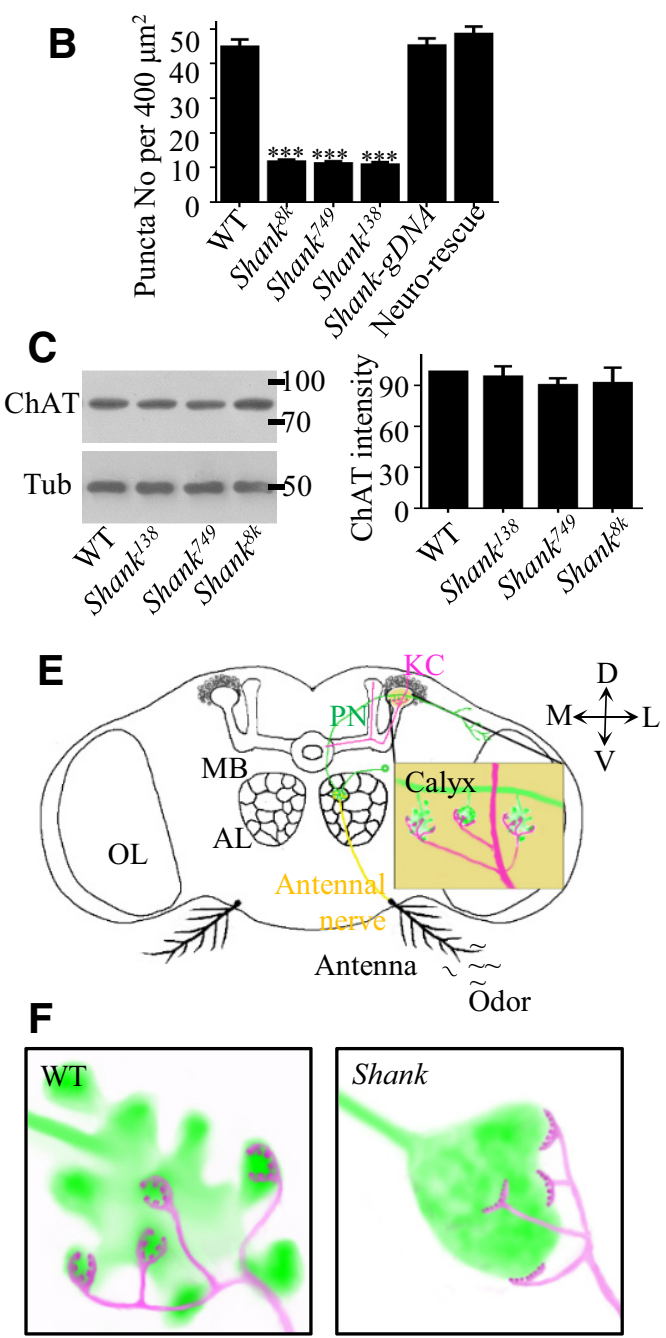

Figure 5. Altered microglomeruli in the adult calyx of Shank mutants. $A$, Single slice confocal images of microglomeruli from different genotypes stained with anti-ChAT. In wild-type controls, most microglomeruli contained evenly distributed, ChAT-positive puncta or protrusions, whereas in Shank ${ }^{8 k}$ mutants, the microglomeruli were more compact, round shaped, and without protrusions. Three microglomeruli within the enlarged view of the boxed area from wild-type controls and Shank ${ }^{8 k}$ mutants were outlined, and a schematic representation of one microglomerulus indicated by an arrow is shown. Microglomeruli defects were rescued by Shank genomic knock-in (Shank-gDNA) or pan neuronal expression of Shank (elav-Gal4/+;Shank ${ }^{8 k}$;UAS-Myc-Shank/+). Scale bar, $5 \mu \mathrm{m}$. B, Statistical results of the number of ChAT-positive puncta per $20 \times 20 \mu \mathrm{m}^{2}$ area in different genotypes. $n=6 .{ }^{* * *} p<0.001$. C, Western results of ChAT in the adult heads of Shank mutants and wild-type control. Right, Statistical results of ChAT protein level in different Shank mutants. $n=3$. D , Single slice confocal images of adult microglomeruli colabeled with anti-ChAT (green) and mb247::D $\alpha 7$-GFP (magenta). Enlarged views of a representative boxed microglomerulus are shown. Scale bar, $5 \mu$ m. $\boldsymbol{E}$, Illustrations of the olfactory processing pathway in the adult brain (modified from Li et al., 2013) and an enlarged view of PN::KC connections in the calyx. F, Schematic depiction of boutons at the PN (green)-KC (magenta) contact site in wild-type control and Shank mutants.

The $\alpha 7$ subunit of nicotinic nAChRs is one of the most prevalent neuronal receptors in the CNS that has been implicated in ASD. Given that PNs are cholinergic (Yasuyama et al., 2002; Leiss et al., 2009; Christiansen et al., 2011), the AChR D $\alpha 7$ subunit was selected to examine synaptic contacts at the MB calyces. Specifically mb247::D $\alpha 7$-GFP, which carries the KC-specific enhancer mb247 upstream of the sequence encoding the AChR subunit D $\alpha 7$ fused to a GFP tag, was used to label the PSD of cholinergic synapses at the MB calyx (Christiansen et al., 2011). To examine synaptic contacts in calyces, adult brains expressing mb247:: D $\alpha 7$-GFP were double-stained with anti-GFP and anti-ChAT (Fig. 5E). In the microglomeruli of wild-type controls, GFPpositive signals appeared as small patches representing postsynaptic sites, which were juxtaposed to individual active zones at PN axonal terminals (Christiansen et al., 2011; Andlauer et al., 2014). The GFP patches in wild-type controls were located adjacent to the ChAT-positive puncta of a distinct bouton (Fig. 5A,D,F), whereas in Shank ${ }^{8 k}$ mutants, the distinct $\mathrm{D} \alpha$-GFP patches were lost and somewhat fused together, consistent with the unilobed microglomeruli revealed by ChAT staining (Fig. $5 A, D, F$ ). Together, these results show that the synaptic contacts at the adult MB calyx were disrupted in Shank mutants.

Ultrastructural defects of synaptic boutons in the adult Shank mutant calyx

The above immunostaining analysis showed abnormal localization of $\mathrm{D} \alpha 7$ and ChAT in the MB calyx of Shank mutants (Figs. 4, 5). To better reveal synaptic defects in Shank mutants, we performed $\mathrm{EM}$ analysis to examine ultrastructures in the adult $\mathrm{MB}$ calyx. The EM profile of microglomeruli in the adult calyx (Fig. $6 A$ ) is consistent with previous reports (Yasuyama et al., 2002; Leiss et al., 2009; Butcher et al., 2012). We observed two major 

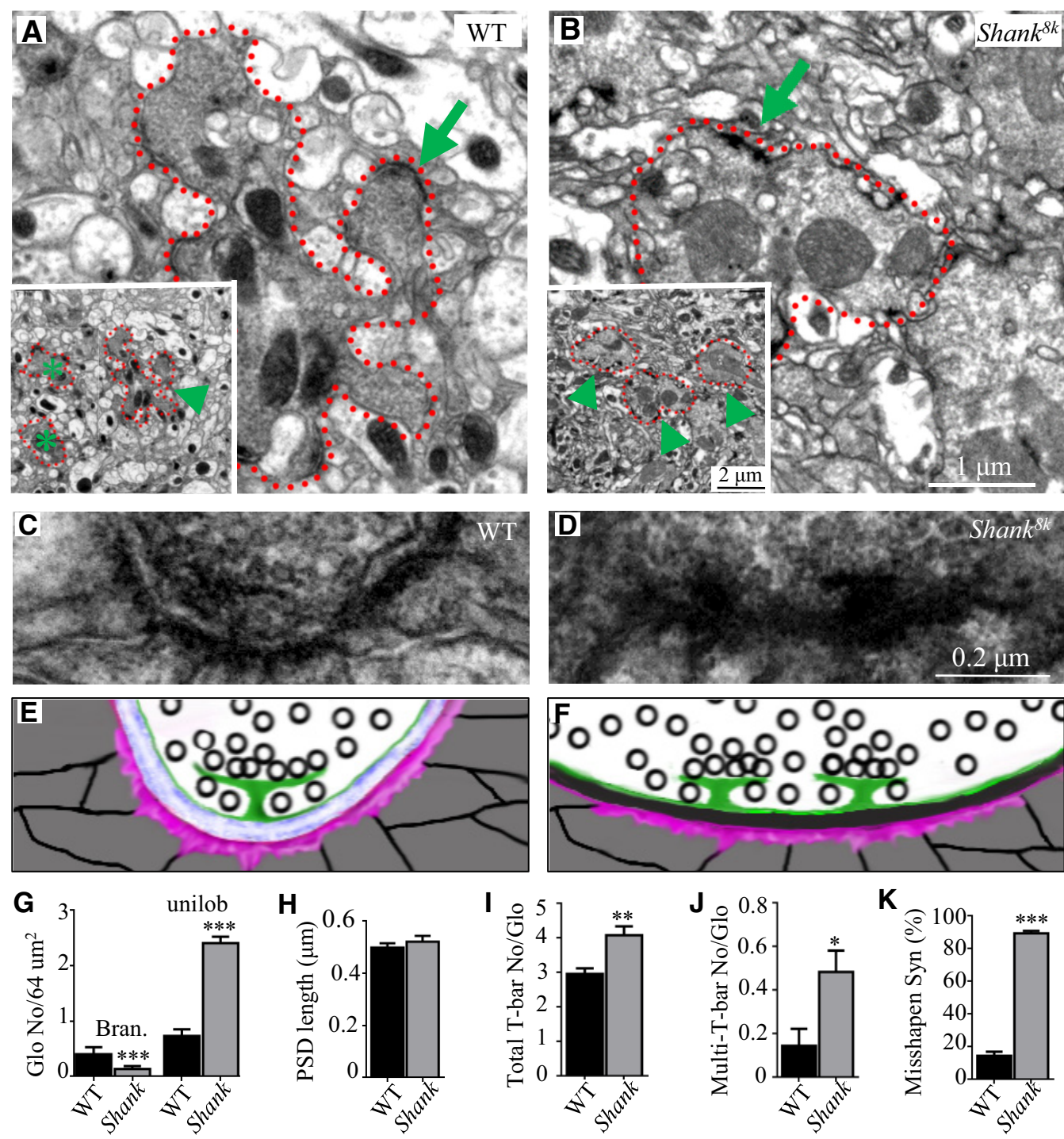

K

Figure 6. Altered ultrastructures in the MB calyx of adult Shank mutants. $\boldsymbol{A}, \boldsymbol{B}$, Electron micrographs of horizontal sections of MB calyx from wild-type controls $(\boldsymbol{A})$ and Shank ${ }^{8 k}$ mutants $(\boldsymbol{B})$. In low-magnification views, two morphologically distinct types of microglomeruli were found: unilobed and clustered; the former indicated round shaped microglomeruli ( $\boldsymbol{B}$, arrowhead), whereas the latter denoted large microglomeruli with multiple protrusions ( $\boldsymbol{A}$, arrowhead). Microglomeruli $<1.2 \times 1.2 \mu \mathrm{m}(\boldsymbol{A}$, asterisks) were not statistically analyzed. High-magnification views show a representative clustered microglomerulus in a wild-type control $(\boldsymbol{A})$ and a representative unilobed microglomerulus in a Shank ${ }^{8 k}$ mutant $(\boldsymbol{B})$. $\boldsymbol{A}, \boldsymbol{B}$, The synapses (arrows) were enlarged in $\boldsymbol{C}, \boldsymbol{D}$, and schematically presented in $\boldsymbol{E}, \boldsymbol{F}$, respectively. Scale bar, $0.2 \mu \mathrm{m}$. Synaptic clefts were clearly seen in wild-type controls $(\boldsymbol{E})$ but were filled with electron-dense materials in $S$ hank ${ }^{8 k}$ mutants $(\boldsymbol{F})$. Green represents T-bar. Pink represents PSD. $\mathbf{G}-\boldsymbol{K}$, Statistical results of the number of branched and unilobed microglomeruli in an area of $64 \mu \mathrm{m}^{2}(\boldsymbol{G}, n \geq 15)$, PSD length $(\boldsymbol{H}, n \geq 35)$, the number of total T-bar $(I, n \geq 20)$, multi-T-bar $(\boldsymbol{J}, n \geq 20)$, and the percentage of misshapen synapses $(\boldsymbol{K}, n \geq 35)$ per microglomerulus. ${ }^{*} p<0.05,{ }^{* *} p<0.01$, ${ }^{* *} p<0.001$. Error bars indicate SEM.

types of boutons: unilobed and clustered; unilobed boutons were single round-shaped boutons with no protrusions, whereas clustered boutons were those with multiple protrusions, each protrusion contains at least one synapse. In the wild-type controls, $26.7 \pm 9.6 \%$ of the boutons were clustered, whereas in Shank ${ }^{8 k}$ mutants, only $5.7 \pm 2.2 \%$ of the boutons were clustered. The number of boutons $>1.2 \mu \mathrm{m}$ in diameter were quantified in an $8 \times 8 \mu \mathrm{m}$ calyx area. Shank mutants showed a reduced number of clustered boutons $(0.40 \pm 0.13$ in wild-type controls vs $0.14 \pm$ 0.05 in Shank ${ }^{8 k}$ mutants, $p<0.001$ ), and an increased number of unilobed boutons compared with wild-type controls $(0.73 \pm 0.10$ in wild-type controls vs $2.24 \pm 0.11$ in Shank ${ }^{8 k}$ mutants, $p<$ 0.001 ; Fig. $6 A, B, G)$, consistent with the staining results in the calyx (Fig. 5A).

Given that Shank is a PSD scaffold protein, we predicted that there might be structural defects in the PSD of Shank mutants. Although the PSD length in Shank mutants appeared normal compared with wild-type $(0.50 \pm 0.02 \mu \mathrm{m}$ in wild-type controls vs $0.52 \pm 0.02 \mu \mathrm{m}$ in Shank ${ }^{8 k}$ mutants, $p=0.459$; Fig. $6 H$ ), synapses were misshapen. Specifically, $\sim 89.20 \pm 1.51 \%$ synaptic clefts were collapsed in Shank $k^{8 k}$ mutants compared with $14.29 \pm$ $2.53 \%$ in wild-type controls $(p<0.001$; Fig. $6 C-F, K)$. The number of total T-bars per microglomerulus was increased in Shank mutants compared with wild-type ( $2.95 \pm 0.16$ in wild-type controls vs $4.07 \pm 0.26$ in Shank ${ }^{8 k}$ mutants, $p=0.0011$; Fig. $6 I$ ), as was the number of multiple T-bars per microglomerulus (0.14 \pm 0.08 in wild-type controls vs $0.48 \pm 0.10$ in Shank ${ }^{8 k}$ mutants, $p=$ 0.012 ; Fig. $6 J$ ). These results demonstrate that synaptic structures are altered in Shank mutants.

Reduced motor ability and defective olfactory acuity in Shank mutants

Compromised locomotion and motor coordination are of the most notable and consistent behavioral abnormalities observed 


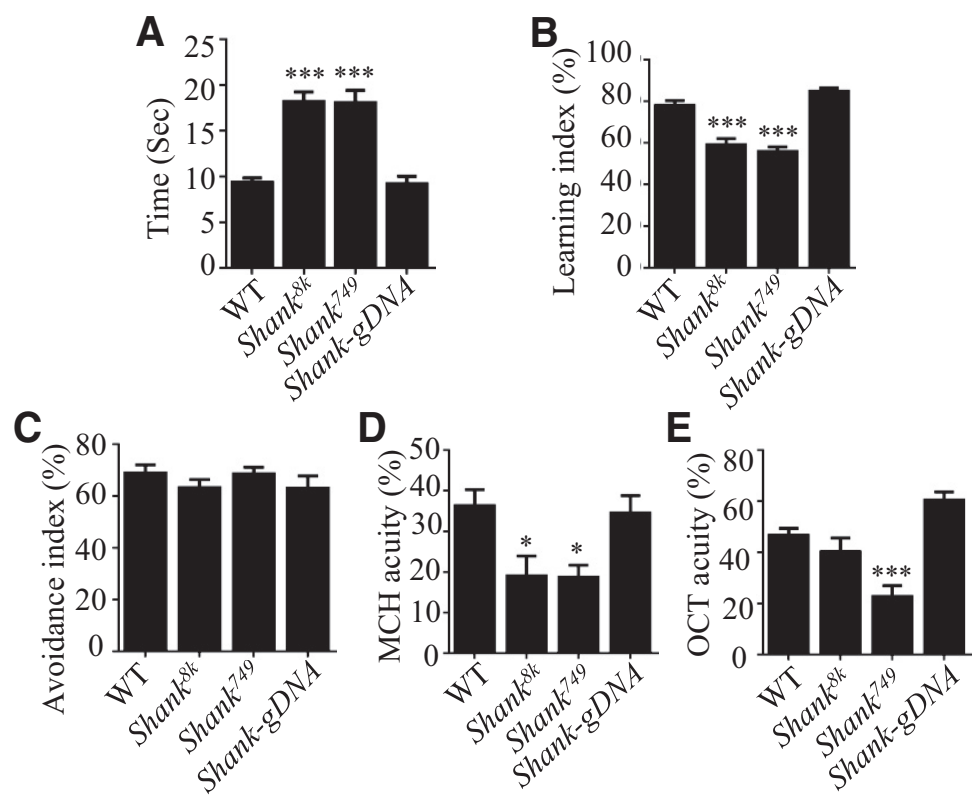

Figure 7. Reduced climbing ability and olfactory acuity in Shank mutants. A, Defective climbing ability in Shank mutants. Shank null mutants performed worse than CS control flies in the climbing test. Genomic Shank-gDNA knock-in rescued the climbing defects found in the null mutants. $\boldsymbol{B}$, Reduced olfactory learning ability of Shank mutants. The learning index in Shank ${ }^{8 k}$ and Shank ${ }^{749}$ mutants was reduced compared with CS controls and was rescued by genomic knock-in of genomic Shank (Shank-gDNA). C, There was no significant difference in the avoidance index in the electric shock response between Shank mutants and CS controls. $\boldsymbol{D}, \boldsymbol{E}$, A decrease in MCH $(\boldsymbol{D})$ and $\mathrm{OCT}(\boldsymbol{E})$ acuity in Shank ${ }^{8 k}$ and Shank ${ }^{749}$ mutants compared with controls. ${ }^{*} p<0.05,{ }^{* * *} p<$ 0.001 .

in Shank3 mutant mice and SHANK3-related patients (Wang et al., 2011, 2016; Soorya et al., 2013; Speed et al., 2015; Zhou et al., 2016). To examine a possible motor coordination defect in Shank mutants, we performed an adult climbing assay. In a group of 20 male flies, the time required for $50 \%$ of the flies pass $15 \mathrm{~cm}$ line was measured. Compared with wild-type controls, Shank mutants climbed slower to cross the $15 \mathrm{~cm}$ line compared with wildtype controls $(9.36 \pm 0.48 \mathrm{~s}$ for wild-type, $18.19 \pm 1.05 \mathrm{~s}$ for Shank $^{8 k}$, and $18.07 \pm 1.35 \mathrm{~s}$ for Shank ${ }^{749}, p<0.001$ for both mutant alleles) (Fig. 7A). Shank-gDNA genomic knock-in rescued the climbing defects found in Shank ${ }^{8 k}$ and Shank ${ }^{749}$ mutants (9.19 $\pm 0.83 \mathrm{~s}$ in Shank-gDNA; $p=0.999$ compared with wildtype), indicating the climbing deficits are specifically associated with Shank mutations.

The MB calyx is associated with olfactory information processing, which involves olfactory acuity, learning, and memory (Christiansen et al., 2011). As synapse development is disrupted in the Shank mutant calyx, we suspected that Shank mutants may show defects in olfactory processing. Results of olfactory learning in the T-maze showed that Shank ${ }^{8 k}$ and Shan ${ }^{749}$ mutants exhibited significantly impaired learning compared with wild-type controls. The learning index was $78.12 \pm 2.06 \%$ for wild-type controls, $59.27 \pm 2.68 \%$ for Shank ${ }^{8 k}$, and $56.01 \pm 1.92 \%$ for Shank ${ }^{79}$ mutants $(p<0.001$ for both mutant alleles). ShankgDNA genomic knock-in rescued the learning defects found in Shank ${ }^{8 k}$ mutants ( $p=0.093$ compared with wild-type) (Fig. $7 B$ ).

Although Shank mutants exhibited normal avoidance upon electric shock stimuli (Fig. 7C), their olfactory acuity to the odor $\mathrm{MCH}$ was significantly lower than the controls (Fig. $7 D$ ). Specifically, the acuity index for MCH was $36.44 \pm 3.77 \%$ in wild-type, $19.14 \pm 4.74 \%$ in Shank ${ }^{8 k}$, and $18.82 \pm 2.82 \%$ in $\operatorname{Shank}^{749}(p=$ 0.018 for Shank $k^{8 k}$ and $p=0.013$ for Shank ${ }^{749}$ ). Shank-gDNA genomic knock-in rescued the olfactory defects found in Shank ${ }^{8 k}$ mutants ( $p=0.006$ compared with wildtype). In the odor test for OCT, the acuity index was $46.82 \pm 2.51 \%$ in wild-type, and $22.88 \pm 4.02 \%$ in Shank ${ }^{749}$, which was significantly reduced $(p<0.001)$, but in Shank $^{8 k}$, the acuity index was $40.37 \pm$ $5.17 \%$, which was not significantly reduced compared with wild-type controls $(p=0.626)$ (Fig. $7 E)$, suggesting that Shank ${ }^{749}$ mutation might exhibit an allele specific function that compromises the OCT acuity. Shank-gDNA knock-in showed normal OCT acuity index compared with wild-type controls ( $p=0.057$ ) (Fig. 7E). The defective olfactory acuity may underlie the learning defects shown above and is consistent with abnormal sensitivity to various stimuli in both SHANK3 patients and mutant mice (Kouser et al., 2013; Monteiro et al., 2017).

\section{Discussion}

\section{The difference in PSD between}

Drosophila NMJ and mammalian excitatory synapses in the CNS

Numerous PSD proteins, including GluRs, ion channels, scaffolding molecules, adhesion molecules, and signaling complexes, have been identified and characterized (Sheng and Hoogenraad, 2007; Sheng and Kim, 2011). With extensive studies of Drosophila NMJs in the last few decades, the only PSD proteins thus far have been characterized are GluRs, the p21-activated kinase PAK, which colocalizes with GluRs and is involved in PSD assembly (Sone et al., 2000; Albin and Davis, 2004; Rasse et al., 2005), and the glutamate receptor auxiliary subunit Neto (Kim et al., 2012). However, to date, there has been no direct evidence that there are mammalian homologs of Drosophila PAK and Neto in PSD components of excitatory synapses in mammalian brain (Kreis and Barnier, 2009; Tomita and Castillo, 2012). Conversely, DLG, the Drosophila homolog of the mammalian PSD-95, is not specifically localized at PSDs, and rather is present in the postsynaptic area characterized by subsynaptic reticulum structures (Koh et al., 1999; Zhang et al., 2007; Thomas et al., 2010). CaMKII, the most abundant mammalian PSD protein at the postsynaptic region in mammals, is not specifically localized at PSDs of Drosophila NMJs (Koh et al., 1999; Zhang et al., 2007). Similarly, endogenous Shank and Homer (Diagana et al., 2002) are not present at PSDs of Drosophila NMJs, although Shank is present at the postsynaptic area (Harris et al., 2016). These observations together suggest a difference of PSD components between NMJ in Drosophila and excitatory synapses in mammalian brains.

Our immunostaining results of synaptic proteins and EM analysis in Shank mutants showed normal PSD structures at NMJ boutons, indicating that Shank does not affect PSD formation at peripheral NMJs. Thus, although Drosophila NMJs have been widely used as an efficient model to study excitatory synapse development, function, and plasticity (Collins and DiAntonio, 2007; Bayat et al., 2011; Harris and Littleton, 2015), a direct comparision between mammalian excitatory synapses at dendritic spines and Drosophila NMJs with respect to PSDs has to be taken with caution. 
Our finding of normal NMJ development and ultrastructure in Shank null mutants is different from an earlier study by Harris et al. (2016), which reports a defective NMJ bouton formation and maturation in Shank ${ }^{D 101}$ mutants. We confirmed the ghost bouton phenotype in Shank ${ }^{D 101}$ mutants, although the phenotype was not severe as reported. In addition, Harris et al. (2016) reported apparent postsynaptic enrichment, whereas we observed a prominent presynaptic localization of Shank at the NMJ boutons. The reason for the discrepancies between two reports is not immediately clear. Of note, the Shank antibodies used for two studies are clearly different. The antibody used for the Harris et al. (2016) study was raised against the peptides of 51-146 aa at $\mathrm{N}$ terminus, whereas we generated the antibody using the antigen of $800-1000$ aa in the middle of Shank protein. As isoform-specific expressions of Shank 3 are well characterized in Shank family protein in mammals (Wang et al., 2014), it is possible that the postsynaptic site-enriched Shank reported by Harris et al. (2016) may represent a short truncated isoform detected by the $\mathrm{N}$ terminus antibody. Alternatively, the difference may be due to the sensitivity and specificity of the two antibodies used in these studies.

The Shank ${ }^{8 k}$ mutation removes the same coding region as Shank $k^{D 101}$, although Shank ${ }^{D 101}$ removes a larger part of the intron between exons 3 and 4 , and part of the $3^{\prime}$-untranslated region. The possibility that this molecular difference and other technical reasons may contribute to the different morphological phenotypes at NMJ of Shank3 mutants remains to be investigated.

\section{Shank regulates central synapse structure in the calyx}

Composed of many glomeruli/microglomeruli, the calyx represents the main olfactory input region of the MB. When LimK, an actin regulator, is overexpressed in KCs, the morphology of the glomerulus rings appeared to be better defined and less irregular (Leiss et al., 2009). Although Homer, Drep-2, and mGluRs are all localized in the PSD of the calyx (Andlauer et al., 2014), it is not known whether there are morphological defects in calyx boutons when one of these genes is mutated. To our knowledge, the present study represents the first report revealing that mutations in a gene result in morphological defects of central synapse in the calyx. The structural defects of Shank mutants in the calyx indicate that Shank plays an important role in synapse development and structure in the brain.

\section{Presynaptic function of Shank is necessary for normal synaptic structure in the brain}

Until now, the presynaptic function of Shank has not been well characterized compared with the extensive studies related to its postsynaptic function. Studies in primary hippocampal neurons revealed that all three SHANKs were detectable in presynaptic specialization of axon terminals; and in particular, SHANK3 was involved in the modulation of NMDA receptor levels at axon terminals (Halbedl et al., 2016). Han et al. (2016) recently reported that SHANK3 expression in presynaptic sites in spinal cord central terminals of DRG neurons plays important roles in pain transduction and transmission via regulation of transient receptor potential ion channel subtype V1. In the present study, we found that Shank was present in both axons and the presynaptic sites of NMJs. In addition, the increased frequency of mEJP, but normal synapse number and EJP amplitudes, in Shank mutants suggest a presynaptic function of Shank. In the central brain, the structural defects in $\mathrm{MB}$ calyces were partially rescued by presynaptic, but not postsynaptic, reexpression of Shank in mutant backgrounds, whereas defects were fully rescued by panneuronal reexpression of Shank. These results support that, in addition to a postsynaptic role, a presynaptic function of Shank is required for the normal synaptic contacts at the MB calyx. How Shank acts in the presynaptic terminus is warranted for further investigation.

Chemical synapses are stabilized in position by synaptic adhesion molecules projecting from both the presynaptic and postsynaptic neurons. Mutations in these molecules, including neuroligins, neurexins, and cadherins, are associated with ASD, supporting a notion that the strength of synaptic adhesion may be compromised (Arons et al., 2012). Additionally, Shank proteins have been identified as a binding partner of neurexin/neuroligin complexes (Meyer et al., 2004); and in particular, alterations in Shank 3 have been shown to provoke changes in synaptic function that requires trans-synaptic signaling through neurexin/neuroligin complexes (Arons et al., 2012). In the present study, ultrastructural analysis of synaptic boutons at Shank mutant calyces showed misorganization of presynaptic and postsynaptic components and lack of synaptic clefts. Thus, our results suggest that Shank may affect presynaptic and postsynaptic apposition via adhesion molecules, such as neuroligins, which physically interacts with Shank in mammals.

\section{References}

Albin SD, Davis GW (2004) Coordinating structural and functional synapse development: postsynaptic p21-activated kinase independently specifies glutamate receptor abundance and postsynaptic morphology. J Neurosci 24:6871-6879. CrossRef Medline

Andlauer TF, Scholz-Kornehl S, Tian R, Kirchner M, Babikir HA, Depner H, Loll B, Quentin C, Gupta VK, Holt MG, Dipt S, Cressy M, Wahl MC, Fiala A, Selbach M, Schwarzel M, Sigrist SJ (2014) Drep-2 is a novel synaptic protein important for learning and memory. Elife 3:e03895. CrossRef Medline

Arons MH, Thynne CJ, Grabrucker AM, Li D, Schoen M, Cheyne JE, Boeckers TM, Montgomery JM, Garner CC (2012) Autism-associated mutations in ProSAP2/Shank3 impair synaptic transmission and neurexin-neuroliginmediated transsynaptic signaling. J Neurosci 32:14966-14978. CrossRef Medline

Bayat V, Jaiswal M, Bellen HJ (2011) The BMP signaling pathway at the Drosophila neuromuscular junction and its links to neurodegenerative diseases. Curr Opin Neurobiol 21:182-188. CrossRef Medline

Berkel S, Tang W, Treviño M, Vogt M, Obenhaus HA, Gass P, Scherer SW, Sprengel R, Schratt G, Rappold GA (2012) Inherited and de novo SHANK2 variants associated with autism spectrum disorder impair neuronal morphogenesis and physiology. Hum Mol Genet 21:344-357. CrossRef Medline

Boeckers TM, Kreutz MR, Winter C, Zuschratter W, Smalla KH, SanmartiVila L, Wex H, Langnaese K, Bockmann J, Garner CC, Gundelfinger ED (1999) Proline-rich synapse-associated protein-1/cortactin binding protein 1 (ProSAP1/CortBP1) is a PDZ-domain protein highly enriched in the postsynaptic density. J Neurosci 19:6506-6518. Medline

Boeckers TM, Liedtke T, Spilker C, Dresbach T, Bockmann J, Kreutz MR, Gundelfinger ED (2005) C-terminal synaptic targeting elements for postsynaptic density proteins ProSAP1/Shank2 and ProSAP2/Shank3. J Neurochem 92:519-524. CrossRef Medline

Butcher NJ, Friedrich AB, Lu Z, Tanimoto H, Meinertzhagen IA (2012) Different classes of input and output neurons reveal new features in microglomeruli of the adult Drosophila mushroom body calyx. J Comp Neurol 520:2185-2201. CrossRef Medline

Christiansen F, Zube C, Andlauer TF, Wichmann C, Fouquet W, Owald D, Mertel S, Leiss F, Tavosanis G, Farca Luna AJ, Fiala A, Sigrist SJ (2011) Presynapses in Kenyon cell dendrites in the mushroom body calyx of Drosophila. J Neurosci 31:9696-9707. CrossRef Medline

Collins CA, DiAntonio A (2007) Synaptic development: insights from Drosophila. Curr Opin Neurobiol 17:35-42. CrossRef Medline

Diagana TT, Thomas U, Prokopenko SN, Xiao B, Worley PF, Thomas JB (2002) Mutation of Drosophila homer disrupts control of locomotor activity and behavioral plasticity. J Neurosci 22:428-436. Medline

Du Y, Weed SA, Xiong WC, Marshall TD, Parsons JT (1998) Identification of a novel cortactin SH3 domain-binding protein and its localization to 
growth cones of cultured neurons. Mol Cell Biol 18:5838-5851. CrossRef Medline

Dubreuil RR, Yu J (1994) Ankyrin and beta-spectrin accumulate independently of alpha-spectrin in Drosophila. Proc Natl Acad Sci U S A 91: 10285-10289. CrossRef Medline

Durand CM, Betancur C, Boeckers TM, Bockmann J, Chaste P, Fauchereau F, Nygren G, Rastam M, Gillberg IC, Anckarsäter H, Sponheim E, GoubranBotros H, Delorme R, Chabane N, Mouren-Simeoni MC, de Mas P, Bieth E, Rogé B, Héron D, Burglen L, et al. (2007) Mutations in the gene encoding the synaptic scaffolding protein SHANK3 are associated with autism spectrum disorders. Nat Genet 39:25-27. CrossRef Medline

Durand CM, Perroy J, Loll F, Perrais D, Fagni L, Bourgeron T, Montcouquiol M, Sans N (2012) SHANK3 mutations identified in autism lead to modification of dendritic spine morphology via an actin-dependent mechanism. Mol Psychiatry 17:71-84. CrossRef Medline

Grabrucker AM, Schmeisser MJ, Schoen M, Boeckers TM (2011) Postsynaptic ProSAP/Shank scaffolds in the cross-hair of synaptopathies. Trends Cell Biol 21:594-603. CrossRef Medline

Halbedl S, Schoen M, Feiler MS, Boeckers TM, Schmeisser MJ (2016) Shank 3 is localized in axons and presynaptic specializations of developing hippocampal neurons and involved in the modulation of NMDA receptor levels at axon terminals. J Neurochem 137:26-32. CrossRef Medline

Han Q, Kim YH, Wang X, Liu D, Zhang ZJ, Bey AL, Lay M, Chang W, Berta T, Zhang Y, Jiang YH, Ji RR (2016) SHANK3 deficiency impairs heat hyperalgesia and TRPV1 signaling in primary sensory neurons. Neuron 92:1279-1293. CrossRef Medline

Harris KP, Littleton JT (2015) Transmission, development, and plasticity of synapses. Genetics 201:345-375. CrossRef Medline

Harris KP, Akbergenova Y, Cho RW, Baas-Thomas MS, Littleton JT (2016) Shank modulates postsynaptic Wnt signaling to regulate synaptic development. J Neurosci 36:5820-5832. CrossRef Medline

Hayashi MK, Tang C, Verpelli C, Narayanan R, Stearns MH, Xu RM, Li H, Sala C, Hayashi Y (2009) The postsynaptic density proteins Homer and Shank form a polymeric network structure. Cell 137:159-171. CrossRef Medline

Huang J, Zhou W, Dong W, Watson AM, Hong Y (2009) From the cover: directed, efficient, and versatile modifications of the Drosophila genome by genomic engineering. Proc Natl Acad Sci U S A 106:8284-8289. CrossRef Medline

Jee C, Lee J, Lee JI, Lee WH, Park BJ, Yu JR, Park E, Kim E, Ahnn J (2004) SHN-1, a Shank homologue in C. elegans, affects defecation rhythm via the inositol-1,4,5-trisphosphate receptor. FEBS Lett 561:29-36. CrossRef Medline

Jiang YH, Ehlers MD (2013) Modeling autism by SHANK gene mutations in mice. Neuron 78:8-27. CrossRef Medline

Kim YJ, Bao H, Bonanno L, Zhang B, Serpe M (2012) Drosophila Neto is essential for clustering glutamate receptors at the neuromuscular junction. Genes Dev 26:974-987. CrossRef Medline

Koh YH, Popova E, Thomas U, Griffith LC, Budnik V (1999) Regulation of DLG localization at synapses by CaMKII-dependent phosphorylation. Cell 98:353-363. CrossRef Medline

Kouser M, Speed HE, Dewey CM, Reimers JM, Widman AJ, Gupta N, Liu S, Jaramillo TC, Bangash M, Xiao B, Worley PF, Powell CM (2013) Loss of predominant Shank3 isoforms results in hippocampus-dependent impairments in behavior and synaptic transmission. J Neurosci 33:1844818468. CrossRef Medline

Kreis P, Barnier JV (2009) PAK signalling in neuronal physiology. Cell Signal 21:384-393. CrossRef Medline

Kremer MC, Christiansen F, Leiss F, Paehler M, Knapek S, Andlauer TF, Forstner F, Kloppenburg P, Sigrist SJ, Tavosanis G (2010) Structural long-term changes at mushroom body input synapses. Curr Boil 20: 1938-1944. CrossRef Medline

Leiss F, Groh C, Butcher NJ, Meinertzhagen IA, Tavosanis G (2009) Synaptic organization in the adult Drosophila mushroom body calyx. J Comp Neurol 17:808-824. CrossRef Medline

Li H, Li Y, Lei Z, Wang K, Guo A (2013) Transformation of odor selectivity from projection neurons to single mushroom body neurons mapped with dual-color calcium imaging. Proc Natl Acad Sci U S A 110:12084-12089. CrossRef Medline

Lim S, Naisbitt S, Yoon J, Hwang JI, Suh PG, Sheng M, Kim E (1999) Characterization of the Shank family of synaptic proteins: multiple genes, alternative splicing, and differential expression in brain and development. J Biol Chem 274:29510-29518. CrossRef Medline

Liu J, Li C, Yu Z, Huang P, Wu H, Wei C, Zhu N, Shen Y, Chen Y, Zhang B, Deng WM, Jiao R (2012) Efficient and specific modifications of the Drosophila genome by means of an easy TALEN strategy. J Genet Genomics 39:209-215. CrossRef Medline

Masuda-Nakagawa LM, Tanaka NK, O’Kane CJ (2005) Stereotypic and random patterns of connectivity in the larval mushroom body calyx of Drosophila. Proc Natl Acad Sci U S A 102:19027-19032. CrossRef Medline

Meyer G, Varoqueaux F, Neeb A, Oschlies M, Brose N (2004) The complexity of PDZ domain-mediated interactions at glutamatergic synapses: a case study on neuroligin. Neuropharmacology 47:724-733. CrossRef Medline

Monteiro P, Feng G (2017) SHANK proteins: roles at the synapse and in autism spectrum disorder. Nat Rev Neurosci 18:147-157. CrossRef Medline

Naisbitt S, Kim E, Tu JC, Xiao B, Sala C, Valtschanoff J, Weinberg RJ, Worley PF, Sheng M (1999) Shank, a novel family of postsynaptic density proteins that binds to the NMDA receptor/PSD-95/GKAP complex and cortactin. Neuron 23:569-582. CrossRef Medline

Osterwalder T, Yoon KS, White BH, Keshishian H (2001) A conditional tissue-specific transgene expression system using inducible GAL4. Proc Natl Acad Sci U S A 98:12596-12601. CrossRef Medline

Palladino MJ, Hadley TJ, Ganetzky B (2002) Temperature-sensitive paralytic mutants are enriched for those causing neurodegeneration in Drosophila. Genetics 161:1197-1208. Medline

Parmentier ML, Pin JP, Bockaert J, Grau Y (1996) Cloning and functional expression of a Drosophila metabotropic glutamate receptor expressed in the embryonic CNS. J Neurosci 16:6687-6694. Medline

Rasse TM, Fouquet W, Schmid A, Kittel RJ, Mertel S, Sigrist CB, Schmidt M, Guzman A, Merino C, Qin G, Quentin C, Madeo FF, Heckmann M, Sigrist SJ (2005) Glutamate receptor dynamics organizing synapse formation in vivo. Nat Neurosci 8:898-905. CrossRef Medline

Ren X, Sun J, Housden BE, Hu Y, Roesel C, Lin S, Liu LP, Yang Z, Mao D, Sun L, Wu Q, Ji JY, Xi J, Mohr SE, Xu J, Perrimon N, Ni JQ (2013) Optimized gene editing technology for Drosophila melanogaster using germ line-specific Cas9. Proc Natl Acad Sci U S A 110:19012-19017. CrossRef Medline

Sato D, Lionel AC, Leblond CS, Prasad A, Pinto D, Walker S, O'Connor I, Russell C, Drmic IE, Hamdan FF, Michaud JL, Endris V, Roeth R, Delorme R, Huguet G, Leboyer M, Rastam M, Gillberg C, Lathrop M, Stavropoulos DJ, et al. (2012) SHANK1 deletions in males with autism spectrum disorder. Am J Hum Genet 90:879-887. CrossRef Medline

Schmeisser MJ, Ey E, Wegener S, Bockmann J, Stempel AV, Kuebler A, Janssen AL, Udvardi PT, Shiban E, Spilker C, Balschun D, Skryabin BV, Dieck St, Smalla KH, Montag D, Leblond CS, Faure P, Torquet N, Le Sourd AM, Toro R, et al. (2012) Autistic-like behaviours and hyperactivity in mice lacking ProSAP1/Shank2. Nature 486:256-260. CrossRef Medline

Sheng M, Hoogenraad CC (2007) The postsynaptic architecture of excitatory synapses: a more quantitative view. Annu Rev Biochem 76:823-847. CrossRef Medline

Sheng M, Kim E (2011) The postsynaptic organization of synapses. Cold Spring Harb Perspect Biol 3:a005678. CrossRef Medline

Sone M, Suzuki E, Hoshino M, Hou D, Kuromi H, Fukata M, Kuroda S, Kaibuchi K, Nabeshima Y, Hama C (2000) Synaptic development is controlled in the periactive zones of Drosophila synapses. Development 127:4157-4168. Medline

Soorya L, Kolevzon A, Zweifach J, Lim T, Dobry Y, Schwartz L, Frank Y, Wang AT, Cai G, Parkhomenko E, Halpern D, Grodberg D, Angarita B, Willner JP, Yang A, Canitano R, Chaplin W, Betancur C, Buxbaum JD (2013) Prospective investigation of autism and genotype-phenotype correlations in 22q13 deletion syndrome and SHANK3 deficiency. Mol Autism 4:18. CrossRef Medline

Speed HE, Kouser M, Xuan Z, Reimers JM, Ochoa CF, Gupta N, Liu S, Powell CM (2015) Autism-associated insertion mutation (InsG) of Shank3 exon 21 causes impaired synaptic transmission and behavioral deficits. J Neurosci 35:9648-9665. CrossRef Medline

Stocker RF, Heimbeck G, Gendre N, de Belle JS (1997) Neuroblast ablation in Drosophila P[GAL4] lines reveals origins of olfactory interneurons. J Neurobiol 32:443-456. CrossRef Medline

Thomas U, Kobler O, Gundelfinger ED (2010) The Drosophila larval neuromuscular junction as a model for scaffold complexes at glutamatergic synapses: benefits and limitations. J Neurogenet 24:109-119. CrossRef Medline 
Tomita S, Castillo PE (2012) Neto1 and Neto2: auxiliary subunits that determine key properties of native kainate receptors. J Physiol 590:22172223. CrossRef Medline

Tully T, Quinn WG (1985) Classical conditioning and retention in normal and mutant Drosophila melanogaster. J Comp Physiol A 157:263-277. CrossRef Medline

Wang X, McCoy PA, Rodriguiz RM, Pan Y, Je HS, Roberts AC, Kim CJ, Berrios J, Colvin JS, Bousquet-Moore D, Lorenzo I, Wu G, Weinberg RJ, Ehlers MD, Philpot BD, Beaudet AL, Wetsel WC, Jiang YH (2011) Synaptic dysfunction and abnormal behaviors in mice lacking major isoforms of Shank3. Hum Mol Genet 20:3093-3108. CrossRef Medline

Wang X, Xu Q, Bey AL, Lee Y, Jiang YH (2014) Transcriptional and functional complexity of Shank3 provides a molecular framework to understand the phenotypic heterogeneity of SHANK3 causing autism and Shank3 mutant mice. Mol Autism 5:30. CrossRef Medline

Wang X, Bey AL, Katz BM, Badea A, Kim N, David LK, Duffney LJ, Kumar S, Mague SD, Hulbert SW, Dutta N, Hayrapetyan V, Yu C, Gaidis E, Zhao S, Ding JD, Xu Q, Chung L, Rodriguiz RM, Wang F, et al. (2016) Altered mGluR5-Homer scaffolds and corticostriatal connectivity in a Shank3 complete knockout model of autism. Nat Commun 7:11459. CrossRef Medline

Yasuyama K, Meinertzhagen IA, Schürmann FW (2002) Synaptic organization of the mushroom body calyx in Drosophila melanogaster. J Comp Neurol 445:211-226. CrossRef Medline

Zars T (2010) Short-term memories in Drosophila are governed by general and specific genetic systems. Learn Mem 17:246-251. CrossRef Medline

Zhang Y, Guo H, Kwan H, Wang JW, Kosek J, Lu B (2007) PAR-1 kinase phosphorylates Dlg and regulates its postsynaptic targeting at the Drosophila neuromuscular junction. Neuron 53:201-215. CrossRef Medline

Zhao L, Wang D, Wang Q, Rodal AA, Zhang YQ (2013) Drosophila cyfip regulates synaptic development and endocytosis by suppressing filamentous actin assembly. PLoS Genet 9:e1003450. CrossRef Medline

Zhou Y, Kaiser T, Monteiro P, Zhang X, Van der Goes MS, Wang D, Barak B, Zeng M, Li C, Lu C, Wells M, Amaya A, Nguyen S, Lewis M, Sanjana N, Zhou Y, Zhang M, Zhang F, Fu Z, Feng G (2016) Mice with Shank3 mutations associated with ASD and schizophrenia display both shared and distinct defects. Neuron 89:147-162. CrossRef Medline 